\title{
Monitoring of Silver Electrodeposition onto HOPG Electrodes in the Presence of Picolinic Acid by in Situ Surface-Enhanced Raman Spectra Measurements
}

\author{
Cecilia I. Vázquez, ${ }^{\dagger}$ Gustavo F. S. Andrade, ${ }^{\S}$ Marcia L. A. Temperini, ${ }^{*, \ddagger}$ and Gabriela I. Lacconi ${ }^{*}{ }^{\dagger}$ \\ †INFIQC CONICET, Departmento de Fisicoquímica, Facultad de Ciencias Químicas, Universidad Nacional de Córdoba, \\ Ciudad Universitaria, RA-5000 Córdoba, Argentina \\ ${ }^{\ddagger}$ Laboratório de Espectroscopia Molecular, Instituto de Química, Universidade de São Paulo, C.P. 26077, CEP 05.513-970, São Paulo, Brazil \\ ${ }^{\S}$ Departamento de Química, Instituto de Ciências Exatas, Universidade Federal de Juiz de Fora, Martelos, CEP 36036-900, \\ Juiz de Fora, Brazil
}

\section{Supporting Information}

\begin{abstract}
In situ surface-enhanced Raman spectra (SERS) have been recorded during silver potentiodynamic electrodeposition onto HOPG electrodes from solutions containing silver perchlorate and picolinic acid (PA). Modification of the composition and $\mathrm{pH}$ of the electrolyte has allowed us to achieve an adequate control of the electroactive species distribution in solution. The adsorption behavior of different PA species on silver growing crystallites has been studied by using the potential dependence of SERS signals. Analysis of the vibrational bands from additive molecules has allowed us to establish that at $\mathrm{pH}>3.0$ the PA anion is the most stable species on the electrode surface, whereas the predominant species in solution is the zwitterion. At $\mathrm{pH} 0.3$, adsorption of zwitterion and anion species onto the silver surface, even though the PA cation is predominant in the solution, has been evidenced. For all the SERS spectra it was possible to infer the adsorption geometry and the $\mathrm{ClO}_{4}{ }^{-}$ion coadsorption. Detection of intensified signals of the adsorbed additive is facilitated by the morphological characteristics of the particles (globular flower-like structures), which results to be a good active SERS substrate on the HOPG electrodes. Spectroelectrochemical experiments are correlated with the SEM micrographs of the silver crystallites.
\end{abstract}

\section{INTRODUCTION}

Electrodeposition of nanostructured silver particles is possible when the electrode material, the electrochemical parameters, and the solution composition to be used during the experiment are carefully selected. ${ }^{1-3}$ Many authors have shown that the application of complex potential-time programs can be used to obtain a good control of the size and distribution of deposited metallic crystals. ${ }^{4,5}$ The influence of organic molecules on the electrodeposition process has been extensively studied to obtain a plated film with determined properties (bright, smooth, rough, etc.). ${ }^{2,6,7}$ When particles are deposited, their characteristics depend on both the composition of the electrolyte and the chemical structure of the additive molecules. Organic molecules with different functional groups act as effective ligands of silver ions, leading to the formation of complex species in solution. ${ }^{8}$ Furthermore, these molecules can be strongly adsorbed either on the electrode surface or on the growing crystallites. Processes such as the complexing reaction and the adsorption of additives have a notable influence on the nucleation reaction rate, resulting in deposits with different morphology. ${ }^{6}$ The adsorption of complex ions and/or additive molecules can be tuned on the substrate by changing only the electrode potential and the additive concentration. In this way, the thermodynamic and kinetic aspects of the metal electrocrystallization depend on these parameters. In fact, it has been demonstrated that the shape, size, and particles distribution on the surface can be successfully controlled by the deposition potential. ${ }^{9}$

Surface-enhanced Raman spectroscopy (SERS) is a highly sensitive and selective method for studying the molecular composition at the electrode/electrolyte interface. In situ SERS measurements can provide information about the chemical structure, orientation, and specific interactions of adsorbed molecules on the electrode surface during the electrochemical process. $^{10-12}$ Commonly, silver electrodes are electrochemically modified (by oxidation-reduction cycles) resulting in a high surface roughness, which has been demonstrated to be highly sensitive for adsorbate detection as active SERS substrates. However, these electrodes show a high degree of surface inhomogeneity. In the present study silver particles were deposited onto HOPG, and SERS experiments were coupled to cyclic voltammetry measurements, to achieve a better insight into the additive participation during electrodeposition. ${ }^{13,14}$

Received: October 23, 2013

Revised: January 31, 2014

Published: February 3, 2014 
Pyridine-carboxylic acid molecules which have carboxyl and pyridinic-nitrogen groups were used to study the silver deposition. The acidic-base functions of these molecules are given by three different species, depending on the solution $\mathrm{pH}$, i.e., protonated, zwitterion, and anion. The influence of picolinic acid (PA) molecules on the nucleation and growth mechanism has been recently studied for copper and silver deposition. ${ }^{15-18}$ The reported results have shown that PA species can be strongly adsorbed on the growing nuclei surface, thereby inhibiting the surface reactivity, and as a consequence, the crystallites grow as dendritic microstructures. Many SERS studies of adsorbed pyridine carboxylic acids on metal substrates have been mainly focused on the effect produced by changing the solution $\mathrm{pH}^{12,19-21}$ and the applied potential, ${ }^{22,23}$ whereas a few publications have been on in situ studies of the electrodeposition process, i.e., formation of a new phase with structures (SERS active sites) that induce preferential adsorption of the additive. ${ }^{6,24-26}$ The aim of this study is the molecular tracking of the picolinic acid molecules during the silver particles electroformation onto HOPG by in situ Raman spectroscopy, under different experimental conditions. Spectroscopic analysis of the adsorbed species from solutions at different $\mathrm{pH}$ has allowed the chemical composition in the electrochemical interface to be correlated to the deposited silver structures.

\section{EXPERIMENTAL SECTION}

2.1. Chemicals. All solutions were prepared from analytical grade reagents and purified water (18.2 M $\mathrm{M} . \mathrm{cm}$ resistivity) using a Millipore Milli-Q system. The electrolyte employed was $1 \mathrm{mM} \mathrm{AgClO}$ (BDH Chemicals Ltd.) in $0.5 \mathrm{M} \mathrm{HClO}_{4}$ (J. T. Baker) at $\mathrm{pH} 0.3$ or in $0.1 \mathrm{M} \mathrm{KClO}_{4}$ at $\mathrm{pH} 3.0$ and 6.5. Solutions with picolinic acid (Sigma-Aldrich) concentrations ranging from 0.5 to $5.0 \mathrm{mM}$ were prepared. The electrolyte $\mathrm{pH}$ was adjusted by addition of $\mathrm{HClO}_{4}$ or $\mathrm{KOH}$ concentrated solutions. All aqueous solutions were freshly prepared and deoxygenated with purified nitrogen prior to each experiment.

Analytical determinations of the PA species in solution were carried out by nuclear magnetic resonance spectroscopy (NMR) with a BRUKER $400 \mathrm{MHz}$ spectrometer (Advance II) and a BBI inverse detection probe. The ${ }^{1} \mathrm{H}$ NMR spectra were recorded for $5.0 \mathrm{mM}$ PA after addition of different amounts of $\mathrm{AgClO}_{4}$ at $\mathrm{pH}$ 3.0 or 6.5 (10\% deuterated water) as was previously detailed. ${ }^{15}$

2.2. Electrochemical Measurements. Potentiodynamic electrodeposition of silver was performed at room temperature in a conventional three-electrode glass cell. Highly oriented pyrolytic graphite (HOPG from SPI Supplies, Brand grade SPI$\left.1,10 \times 10 \mathrm{~mm}^{2}\right)$, sealed into a Teflon holder $\left(0.283 \mathrm{~cm}^{2}\right)$, was used as the working electrode. The basal plane surface of HOPG was cleaved using adhesive tape immediately prior to use. A Pt wire and a silver wire immersed in the $\mathrm{Ag}^{+}$electrolyte were the counter and quasi-reference electrodes, respectively. All potentials are reported versus the $\mathrm{Ag}^{0} / \mathrm{Ag}^{+}(1 \mathrm{mM})$ reference electrode $\left(E_{\mathrm{Ag}^{0} / \mathrm{Ag}+}=-0.30 \mathrm{~V}\right.$ vs the potential of saturated calomel electrode). Reproducible initial states of the HOPG surface were obtained by applying a pulse at $0.4 \mathrm{~V}$ for $1 \mathrm{~min}$, prior to each experiment. ${ }^{27,28}$ Cyclic voltammetry experiments were performed at very low scan rates, starting from $0.4 \mathrm{~V}$ with the scan directed towards negative potentials by using a computer-controlled potentiostat Autolab PGSTAT with GPES software (ECO CHEMIE B.V.).

2.3. Raman and SERS Spectroscopic Measurements. Raman and SERS spectra were measured with a confocal microRaman spectrometer (Renishaw InVia system), equipped with a Leica microscope and a $63 \times$ water immersion objective
$(\mathrm{NA}=0.9)$. The excitation line was $632.8 \mathrm{~nm}$ (from $\mathrm{He}-\mathrm{Ne}$ laser) with 0.3 or $3.5 \mathrm{~mW}$ laser power for SERS or normal Raman spectra, respectively. The illuminated area in all Raman experiments was $1.0 \mu \mathrm{m}^{2}$.

Ex situ SERS experiments were performed with a drop of $5.0 \mathrm{mM}$ PA or $0.5 \mathrm{mM} \mathrm{PA}+1.0 \mathrm{mM} \mathrm{AgClO}_{4}$ (at pH 0.3, 3.0, or 6.5) solution, deposited onto the HOPG electrodes containing silver crystallites, which were deposited by a potential scan from 0.4 to $-0.4 \mathrm{~V}$ and reversing up to $-0.1 \mathrm{~V}$ in $1 \mathrm{mM} \mathrm{AgClO}_{4}+0.1 \mathrm{M}$ $\mathrm{KClO}_{4}(\mathrm{pH} \mathrm{3.0)}$ solution. The in situ SERS spectra were carried out simultaneously with the potentiodynamic scan (at $1 \mathrm{mV} \mathrm{s}^{-1}$ ) for silver crystallite deposition $\mathrm{HClO}_{4}\left(\mathrm{KClO}_{4}\right)+\mathrm{AgClO}_{4}+\mathrm{PA}$ solutions at $\mathrm{pH} 0.3,3.0$, and 6.5 in a homemade-Teflon cell specially designed for the confocal microscope configuration. Samples of HOPG were fixed to the bottom of the cell (circular area with a $0.72 \mathrm{~cm}$ diameter). A Pt wire loop (concentric with the working electrode) and a $\mathrm{Ag}$ wire were employed as the counter and quasi-reference electrodes, respectively. The setup used for the Raman scattering acquisition mode included $10 \mathrm{~s}$ accumulation for each point in the spectra. The electrochemical control was performed with a potentiostat/galvanostat EG\&G PAR-273 interfaced to a computer, the potential for each synchronized spectroelectrochemical experiment being recorded at the end of each accumulated spectrum. The experimental setup for the in situ spectroscopy was checked by the potentiodynamic and potentiostatic measurements with results identical to those obtained in a conventional cell. Raman spectra were represented as relative intensities of the signals, taking as a reference the symmetric stretching of $\mathrm{ClO}_{4}^{-}$ions $\left(932 \mathrm{~cm}^{-1}\right)$ except where absolute values are specified.

2.4. Morphological Characterization. The morphology of silver crystallites was examined using a Field Emission Gun Scanning Electron Microscope (FEG-SEM) JEOL JSM-7401F. Images were acquired in the backscattered electron mode with $5 \mathrm{kV}$ acceleration voltage and a filament current of $10 \mu \mathrm{A}$.

2.5. Computational Details. For the assignments of PA vibrational modes in solution, theoretical calculations were carried out by the DFT method, with the exchange correlation functional B3LYP and the triple- $\zeta$ basis function set CEP121G, ${ }^{29,30}$ as set up in the Gaussian09 suite of programs. ${ }^{31-33}$ All model chemistries were optimized without any constraints, with a local minimum being ascertained by the absence of any imaginary vibrational frequency. When it was necessary to plot the calculated Raman intensities, these were corrected for temperature and finite frequency. ${ }^{34}$

\section{RESULTS AND DISCUSSION}

3.1. Chemical Characteristics of Picolinic Acid (PA). 2Pyridine carboxylic acid (picolinic acid, PA) has two functional groups, the carboxylic group in the $\alpha$-position and the pyridinic nitrogen, whose acid equilibrium constants are $\mathrm{p} K_{\mathrm{a} 1}=1.03$ and $\mathrm{p} K_{\mathrm{a} 2}=5.21$, respectively. ${ }^{35}$ Depending on the solution $\mathrm{pH}$ and the PA analytical concentration, three different chemical identities, namely, ${ }^{+} \mathrm{HNC}_{5} \mathrm{H}_{6} \mathrm{COOH}\left(\mathrm{H}_{2} \mathrm{Pic}^{+}\right)$, ${ }^{+} \mathrm{HNC}_{5} \mathrm{H}_{6} \mathrm{COO}^{-}$ (HPic), and $\mathrm{NC}_{5} \mathrm{H}_{6} \mathrm{COO}^{-}\left(\right.$Pic $\left.^{-}\right)$, can be found in aqueous solutions (see sequence of reaction 1)

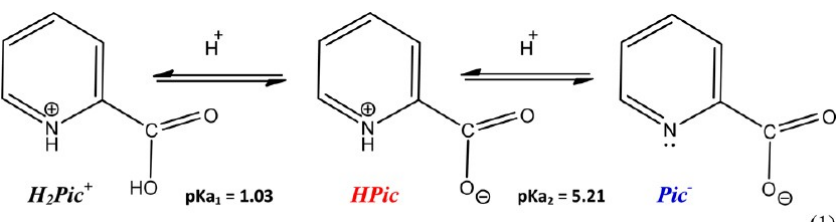

To study the silver electrodeposition mechanism in the presence of different PA species, the chemical identification of 
molecules in the electrolyte and adsorbed on the electrode surface is required. Silver was electrodeposited in solutions at $\mathrm{pH} 0.3,3.0$, and 6.5, where the equilibrium concentration of protonated $\mathrm{H}_{2} \mathrm{Pic}^{+}$, zwitterion $\mathrm{HPic}$, and anion $\mathrm{Pic}^{-}$species is predominant, respectively (see Figure $S 1$ in the Supporting Information). Raman spectra of $0.15 \mathrm{M} \mathrm{PA}$ in $0.5 \mathrm{M} \mathrm{HClO}_{4}$ ( $\mathrm{pH} 0.3$ ) or $0.1 \mathrm{M} \mathrm{KClO}_{4}(\mathrm{pH} 3.0$ and 6.5) solutions are shown in Figure 1. Table 1 contains the Raman bands from Figure 1

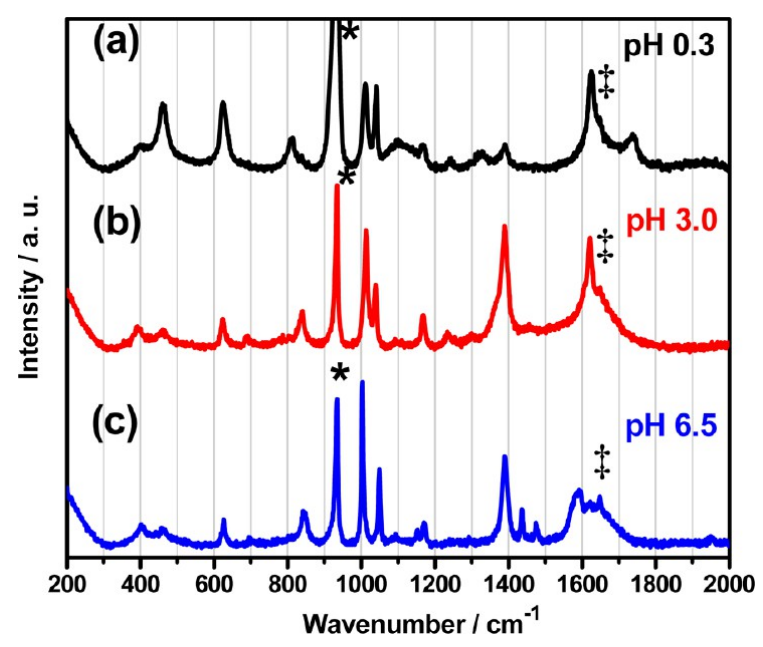

Figure 1. Raman spectra of PA $(0.15 \mathrm{M})$ in (a) $0.5 \mathrm{M} \mathrm{HClO}_{4}$ ( $\mathrm{pH} 0.3$ ) or $0.1 \mathrm{M} \mathrm{KClO}_{4}$ (b) at $\mathrm{pH} 3.0$ and (c) at $\mathrm{pH} 6.5$ aqueous solutions. (*) Main Raman band from $\mathrm{ClO}_{4}{ }^{-}$ions. (\$) Signal at $1648 \mathrm{~cm}^{-1}$ from the $632.8 \mathrm{~nm}$ laser plasma.

and their assignments, which were obtained by computational calculations based on DFT for each chemical identity (considering a model with individual molecules in vacuum) and by comparing with the Raman spectra of PA solutions in the literature. ${ }^{19,36,37}$

All Raman spectra have an intense signal at $933 \mathrm{~cm}^{-1}$ corresponding to the $\mathrm{Cl}-\mathrm{O}$ stretching vibration from the supporting electrolyte, which was used as the internal standard for the spectral normalization in the SERS experiments discussed below. ${ }^{38}$

Protonation of both functional groups of PA was detected by the presence of Raman bands associated with the corresponding vibrational modes of the different species. When the $\mathrm{pH}$ is 0.3 , the characteristic Raman signals of the $\mathrm{H}_{2} \mathrm{Pic}^{+}$species are those at $810 \mathrm{~cm}^{-1}$ (ring breathing + stretching of the C$\mathrm{COOH}$ bond) and $1736 \mathrm{~cm}^{-1}$ (symmetric stretching of the $\mathrm{C}=\mathrm{O}$ group). ${ }^{37}$

The spectra of PA solutions at $\mathrm{pH} 3.0$ and 6.5 show the band associated to the stretching of the $\mathrm{C}-\mathrm{COO}$ bond combined with in-plane bending of the COO group at 838 and $845 \mathrm{~cm}^{-1}$, respectively. Evidence found of the carboxylic group deprotonation can be explained by the molecular symmetry present in the electron clouds of both indistinguishable $\mathrm{C}-\mathrm{O}$ bonds, in the zwitterion and anion species. Another feature is the presence of a strong signal at $1389 \mathrm{~cm}^{-1}$ (combined vibrational mode $\nu_{\mathrm{s}}(\mathrm{COO})+\beta(\mathrm{CH})+\beta(\mathrm{NH})$ or $\left.\nu_{\mathrm{s}}(\mathrm{COO})+\beta(\mathrm{CH})\right)$ in the spectra, where $\mathbf{H P i c}$ and $\mathbf{P i c}^{-}$are the predominant species (Figure $1 \mathrm{~b}$ and $\mathrm{c}$, respectively). However, this signal (very weak) is also present at $\mathrm{pH} 0.3$ (Figure 1a), which is due to a small amount of zwitterion coming from the acid-base equilibrium (around 16\% of the PA analytical concentration). The band at $1011 \mathrm{~cm}^{-1}$ in the cation and zwitterion spectra was attributed to the trigonal ring breathing mode $(\nu 12)$, in agreement with the assignments given by Sala and coworkers. $^{36}$ This signal is shifted to a lower wavenumber $\left(1003 \mathrm{~cm}^{-1}\right)$ when the pyridine nitrogen is not protonated. In contrast, the bands at 1040 and $1038 \mathrm{~cm}^{-1}$ for $\mathrm{H}_{2} \mathrm{Pic}^{+}$and $\mathrm{HPic}$ are shifted to higher wavenumbers in the anion spectrum, indicating that the band position is highly sensitive to protonated nitrogen in the aromatic ring. ${ }^{36}$ Moreover, the $\nu 19 \mathrm{~b}$ and 19a ring combined modes appeared distinctly at 1437 and $1475 \mathrm{~cm}^{-1}$, respectively, but only in the $\mathrm{Pic}^{-}$anion spectrum.

3.2. Formation of Silver(I)-PA Complexes in Solution. The feasibility to form soluble complexes with $\mathrm{Ag}^{+}$ions depends on the predominant PA species in the solution. In addition, the concentration of $[\boldsymbol{A g}(\mathrm{L})]^{+}$complexes in solution, with $\mathrm{H}_{2} \mathrm{Pic}^{+}, \mathrm{HPic}$, and $\mathrm{Pic}^{-}$species as the ligand $\mathbf{L}$, could be regulated by changing the $\mathrm{pH}$ and the ratio between $\mathrm{PA}$ and $\mathrm{Ag}^{+}$ion concentrations. Thus, reactions 2 to 4 for the 1:1 complexes formation can occur under different experimental conditions.

$$
\begin{aligned}
& \mathrm{Ag}^{+}+\mathrm{H}_{2} \mathrm{Pic}^{+} \leftrightarrows\left[\mathrm{Ag}\left(\mathrm{H}_{2} \mathrm{Pic}\right)\right]^{2+} \\
& \mathrm{Ag}^{+}+\text {HPic } \leftrightarrows[\mathrm{Ag}(\text { HPic })]^{+} \\
& \mathrm{Ag}^{+}+\mathrm{Pic}^{-} \leftrightarrows[\mathrm{Ag}(\text { Pic })]
\end{aligned}
$$

To determine the electroactive species involved in the electrodeposition process, it was necessary to identify the complex species present during the electrochemical experiment. To carry this out, Raman spectra of $0.15 \mathrm{M} \mathrm{PA}+0.15 \mathrm{M} \mathrm{Ag}^{+}$ solutions at the three selected $\mathrm{pH}$ 's were recorded. At $\mathrm{pH} 0.3$, the spectrum (results not shown) was identical to that of Figure 1a; therefore, the formation of $\left[\mathrm{Ag}\left(\mathrm{H}_{2} \mathrm{Pic}\right)\right]^{2+}$ complexes (reaction 2) was not considered $\left(\mathbf{H}_{2} \mathbf{P i c}^{+}\right.$has no available groups to interact with $\mathrm{Ag}^{+}$ions). On the other hand, Raman spectra of $[\boldsymbol{A g}(\mathbf{H P i c})]^{+}$and $[\boldsymbol{A g}(\mathbf{P i c})]$ complexes could not be obtained since very high concentrations (much higher than the limit of solubility) were required for their detection.

The molecular structure and the stability constants of both $[\mathbf{A g}(\mathbf{H P i c})]^{+}$and $[\mathbf{A g}(\mathbf{P i c})]$ complexes were established by analysis of nuclear magnetic resonance $\left({ }^{1} \mathrm{H}\right.$ NMR) spectra at $\mathrm{pH} 3.0$ and 6.5 as was described previously. ${ }^{15}$ The comparative analysis of the spectra (results not shown) of the $5.0 \mathrm{mM}$ PA solution after addition of different amounts of $\mathrm{Ag}^{+}$ions permitted us to establish that: (i) Both HPic and $\mathrm{Pic}^{-}$ligands interact with $\mathrm{Ag}^{+}$ions through the carboxylate group and (ii) the stability constants for 1:1 complexes, given by reactions 3 and 4 .

$$
\begin{aligned}
& \mathrm{Ag}^{+}+\text {HPic } \\
& \leftrightarrows {[\boldsymbol{A g}(\text { HPic })]^{+} } \\
& \mathrm{K}_{[\boldsymbol{A g}(\boldsymbol{H P i c})]+}(\mathrm{pH} \mathrm{3.0})=(11.5 \pm 0.6) \mathrm{M}^{-1} \\
& \mathrm{Ag}^{+}+\boldsymbol{P i c}^{-} \leftrightarrows {[\boldsymbol{A g}(\boldsymbol{P i c})] } \\
& \mathrm{K}_{[\text {Ag(Pic })]}(\mathrm{pH} 6.5)=(800 \pm 100) \mathrm{M}^{-1}
\end{aligned}
$$

By considering the acid dissociation and complex stability constants, the chemical composition of the electrolytes at different $\mathrm{pH}$ and analytical concentrations of PA could be established (Table 2). Data in Table 2 show that at $\mathrm{pH} 0.3$ the content of complex species in solution was negligible in all cases, whereas $\mathrm{Ag}^{+}$ions remained almost completely uncomplexed when the zwitterion species was predominant (at $\mathrm{pH}$ 3.0). Moreover, although the equilibrium concentrations 
Table 1. Wavenumbers (in $\mathrm{cm}^{-1}$ ) and Vibrational Assignments of the Normal Raman and Ex Situ SERS Spectra of PA at Different $\mathrm{pH}^{c}$

\begin{tabular}{|c|c|c|c|c|c|c|c|}
\hline \multicolumn{7}{|c|}{ Wavenumber $/ \mathrm{cm}^{-1}$} & \multirow[b]{3}{*}{ Assignment $^{(\mathrm{a})}$} \\
\hline \multicolumn{3}{|c|}{ Normal Raman } & \multicolumn{4}{|c|}{ ex-situ SERS } & \\
\hline $\begin{array}{l}\mathrm{pH} 0.5 \\
\mathrm{H}_{2} \mathrm{PiC}^{+}\end{array}$ & $\begin{array}{l}\mathrm{pH} 3.0 \\
\text { HPic }\end{array}$ & $\begin{array}{c}\mathrm{pH} 6.5 \\
\text { Pic }^{-}\end{array}$ & $\begin{array}{c}\text { PA } \\
\text { pH } 3.0\end{array}$ & $\begin{array}{c}\text { PA } \\
\text { pH } 6.5\end{array}$ & $\begin{array}{l}\mathrm{Ag}-\mathrm{PA} \\
\mathrm{pH} 3.0\end{array}$ & $\begin{array}{l}\text { Ag-PA } \\
\text { pH } 6.5\end{array}$ & \\
\hline & & & 244 (169) & $230(205)$ & 242 & 237 & Ag-N $(A g-O)$ stretching $^{(b)}$ \\
\hline 401 & 394 & 402 & & & & & $\begin{array}{l}\delta(\mathrm{OCO}(\mathrm{H})) \\
v(\mathrm{C}-\mathrm{COO}) \\
v(\mathrm{C}-\mathrm{COO})(16 \mathrm{~b})\end{array}$ \\
\hline 460 & 458 & 461 & & & 443 & 432 & $\beta_{5}(\mathrm{Cl}-\mathrm{O})$ from $\mathrm{ClO}_{4}{ }^{-}$ions \\
\hline 625 & 623 & 626 & & 637 & 637 & 638 & $\beta_{a}(\mathrm{Cl}-\mathrm{O})$ from $\mathrm{ClO}_{4}$ ions \\
\hline 810 & 838 & 845 & 845 (815) & $844(788)$ & 846 & 845 & \begin{tabular}{|l} 
Ring breathing $(1)+v(\mathrm{C}-\mathrm{COOH})$ \\
$v(\mathrm{C}-\mathrm{COO})+\delta$ (in-plane ring) \\
$\delta(\mathrm{COO})+\delta$ (in-plane ring $)(6 \mathrm{~b})$ \\
$v(\mathrm{C}-\mathrm{COO})+\delta(\mathrm{OCO})^{(b)}$
\end{tabular} \\
\hline 932 & 933 & 934 & 933 & 934 & 933 & 932 & $v_{\mathrm{s}}(\mathrm{Cl}-\mathrm{O})$ from $\mathrm{ClO}_{4}{ }^{-}$ions \\
\hline 1011 & 1012 & 1003 & 1014 & 1014 & 1015 & 1014 & \begin{tabular}{|l}
$v_{12}$ (trigonal ring breathing) \\
$v_{12}$ (trigonal ring breathing) \\
$v_{12}$ (trigonal ring breathing) \\
\end{tabular} \\
\hline 1040 & 1038 & 1049 & $\begin{array}{c}1053 \\
(1050)\end{array}$ & $\begin{array}{c}1052 \\
(1050)\end{array}$ & $\begin{array}{c}1037 \\
(1052) \\
\end{array}$ & $\begin{array}{c}1035 \\
(1053) \\
\end{array}$ & $\begin{array}{l}\beta(\mathrm{CH})+v(\mathrm{CC})+\beta(\mathrm{NH}) \\
\beta(\mathrm{CH})+v(\mathrm{CC})+\beta(\mathrm{NH}) \\
\beta(\mathrm{CH})\end{array}$ \\
\hline & & 1153 & & 1128 & & & $\beta(\mathrm{CH})+v(\mathrm{C}-\mathrm{COO})+v_{s}(\mathrm{COO})$ \\
\hline 1167 & 1168 & 1170 & 1170 & 1169 & 1171 & 1169 & $\begin{array}{l}v(\mathrm{C}-\mathrm{COOH})+\beta(\mathrm{OH}) \\
\beta(\mathrm{CH}) \\
\beta(\mathrm{CH})\end{array}$ \\
\hline 1244 & 1234 & & & & & & $\begin{array}{l}\beta(\mathrm{CH}) \\
v(\mathrm{C}-\mathrm{COO})+v_{s}(\mathrm{COO})\end{array}$ \\
\hline & & & & 1301 & 1295 & 1306 & $v_{s}(\mathrm{COO})+V(C-N)^{(b)}$ \\
\hline & 1389 & 1389 & $\begin{array}{c}1385 \\
(1394)\end{array}$ & $\begin{array}{c}1384 \\
(1294)\end{array}$ & 1385 & 1380 & $\begin{array}{l}v_{s}(\mathrm{COO})+\beta(\mathrm{CH})+\beta(\mathrm{NH}) \\
\mathrm{v}_{\mathrm{s}}(\mathrm{COO})+\beta(\mathrm{CH})\end{array}$ \\
\hline & & 1437 & 1440 & $\begin{array}{l}1440 \\
(1445)\end{array}$ & 1440 & 1439 & $v(C C, C N)(19 b)+\beta(C H)$ \\
\hline & & 1475 & 1474 & $\begin{array}{c}1474 \\
(1474)\end{array}$ & 1473 & 1473 & $v(C C, C N)(19 a)+\beta(C H)$ \\
\hline & & & 1580 & 1580 & 1575 & 1579 & $G$ mode from $H O P G^{(b)}$ \\
\hline & & 1592 & & & 1597 & 1599 & $v(C C)(8 b)+v_{a}(\mathrm{COO})$ \\
\hline 1625 & 1621 & 1621 & & & & & $\begin{array}{l}\mid v(C C)(8 a) \\
v(C C)(8 a) \\
v(C C)(8 a)\end{array}$ \\
\hline 1736 & & & & & & & $v_{s}(C=0)$ \\
\hline
\end{tabular}

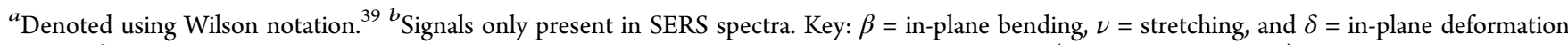
modes. ${ }^{c}$ Assignments of the main PA vibrational modes were obtained by DFT calculations (between parentheses) and by referring to the literature. ${ }^{36,37}$ For comparison, data from PA solutions at $\mathrm{pH} 6.5$ (Table 1) were included.

were very low, the amount of $[\mathbf{A g}(\mathbf{H P i c})]^{+}$was slightly higher than that of $\mathrm{Pic}^{-}$or $[\mathrm{Ag}(\mathrm{Pic})]$ in every case. Finally, the predominant species at $\mathrm{pH} 6.5$ were the uncomplexed $\mathbf{P i c}^{-}$ species, $\mathrm{Ag}^{+}$ions, and $[\mathrm{Ag}(\boldsymbol{P i c})]$ complexes. Thus, the electroactive species composition in the electrolyte depends on the analytical concentration of the additive and the solution $\mathrm{pH}$. Standard potentials for the electroreduction of the complex species were estimated with the values of stability constants given in eqs 3 and 4 (see section S.2. in the Supporting Information).

3.3. Ex Situ SERS Spectra of PA Adsorbed on Ag Crystallites. To obtain information on the chemical identity of the PA molecules and complex species when they are adsorbed on the surface of silver crystallites, SERS spectra were recorded after casting a drop of $5.0 \mathrm{mM} \mathrm{PA}$ (Figure $2 \mathrm{a}$ ) or $0.5 \mathrm{mM} \mathrm{PA}+1.0 \mathrm{mM}$
$\mathrm{AgClO}_{4}$ (Figure 2b) solutions at different $\mathrm{pH}$ onto HOPG modified with the Ag deposit. New silver crystallites were deposited on the substrate in each experiment, which is the reason it was not possible to achieve a quantitative comparison between the spectra. It is important to note that no SERS spectra of PA molecules (results not shown) were observed on the HOPG surface free of crystallites because the graphite surface is not SERS-active and the PA solutions were very diluted $\left(10^{-3} \mathrm{M}\right)$. Thus, the supported silver crystallites were the SERS active centers which allowed the detection of PA vibrational modes in the ex situ configuration.

Experimental values of the frequencies of the ex situ SERS spectra of $\mathrm{PA}$ and $[\boldsymbol{A g}(\boldsymbol{L})]^{+}$complexes adsorbed on the crystallites at $\mathrm{pH} 3.0$ and 6.5 (Figure 2) are shown in Table 1. Assignments of the SERS bands were performed by comparison 
Table 2. Concentrations at Equilibrium of PA Species Present in $1.0 \mathrm{mM} \mathrm{AgClO}$ Solutions with Different PA Concentrations and $\mathrm{pH}^{a}$

\begin{tabular}{|c|c|c|c|c|c|c|c|}
\hline \multirow{2}{*}{$\mathrm{pH}$} & \multirow{2}{*}{$\begin{array}{c}\text { PA } \\
\text { analytical } \\
\text { concentr. } \\
/ \mathrm{mM}\end{array}$} & \multicolumn{6}{|c|}{ Equilibrium concentrations / $\mathbf{m M}$} \\
\hline & & $\mathbf{A g}^{+}$ & $\mathrm{H}_{2} \mathrm{Pic}^{+}$ & HPic & $P i c^{-}$ & {$[\mathbf{A g}(\text { HPic })]^{+}$} & {$[\mathrm{Ag}(P i c)]$} \\
\hline \multirow{3}{*}{0.3} & 0.5 & 0.999 & 0.421 & $7.8 \times 10^{-2}$ & $9.64 \times 10^{-7}$ & $9.08 \times 10^{-4}$ & $7.70 \times 10^{-7}$ \\
\hline & 1.0 & 0.998 & 0.842 & 0.157 & $1.93 \times 10^{-6}$ & $1.81 \times 10^{-3}$ & $1.54 \times 10^{-6}$ \\
\hline & 5.0 & 0.991 & 4.208 & 0.784 & $9.64 \times 10^{-6}$ & $9.01 \times 10^{-3}$ & $7.64 \times 10^{-6}$ \\
\hline \multirow{3}{*}{3.0} & 0.5 & 0.992 & $5.19 \times 10^{-3}$ & 0.484 & $2.99 \times 10^{-3}$ & $5.57 \times 10^{-3}$ & $2.37 \times 10^{-3}$ \\
\hline & 1.0 & 0.984 & $1.04 \times 10^{-2}$ & 0.968 & $5.97 \times 10^{-3}$ & $1.11 \times 10^{-2}$ & $4.70 \times 10^{-3}$ \\
\hline & 5.0 & 0.926 & $5.19 \times 10^{-2}$ & 4.844 & $2.99 \times 10^{-2}$ & $5.20 \times 10^{-2}$ & $2.21 \times 10^{-2}$ \\
\hline \multirow{3}{*}{6.5} & 0.5 & 0.809 & $5.11 \times 10^{-8}$ & $1.51 \times 10^{-2}$ & 0.294 & $1.42 \times 10^{-4}$ & 0.191 \\
\hline & 1.0 & 0.664 & $1.10 \times 10^{-7}$ & $3.24 \times 10^{-2}$ & 0.632 & $2.50 \times 10^{-4}$ & 0.336 \\
\hline & 5.0 & 0.237 & $7.0010^{-7}$ & 0.207 & 4.030 & $5.67 \times 10^{-4}$ & 0.763 \\
\hline
\end{tabular}

${ }^{a}$ Values calculated considering the acid dissociation (sequence of reactions 1 ) and the complex stability (reactions 3 and 4 ) constants. Predominant species concentrations are shaded in the table.

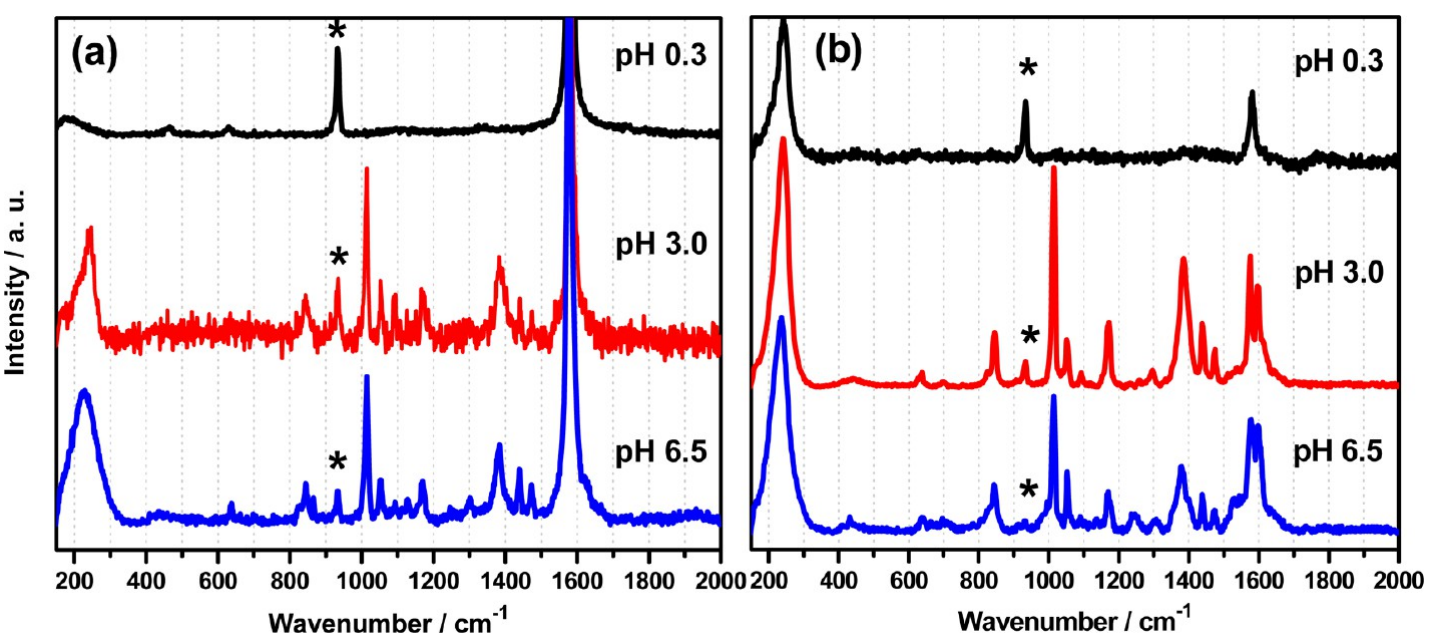

(c)

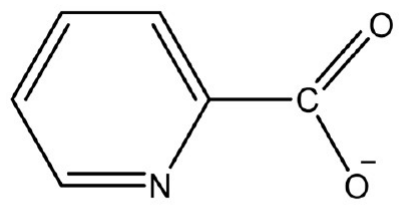

\section{$\mathbf{A g}^{\mathbf{0}}$ crystallite surface}

Figure 2. Ex situ SERS spectra of PA adsorbed on silver crystallites deposited on HOPG electrodes, from a solution containing (a) $5.0 \mathrm{mM} \mathrm{PA}$ in $0.5 \mathrm{M} \mathrm{HClO}_{4}\left(\mathrm{pH} 0.3\right.$ ) or in $0.1 \mathrm{M} \mathrm{KClO}_{4}\left(\mathrm{pH} 3.0\right.$ and 6.5) and (b) $0.5 \mathrm{mM} \mathrm{PA}+1.0 \mathrm{mM} \mathrm{AgClO}_{4}$ in $0.5 \mathrm{M} \mathrm{HClO}_{4}(\mathrm{pH} 0.3$ ) or in $0.1 \mathrm{M} \mathrm{KClO}_{4}(\mathrm{pH} 3.0$ and 6.5). Silver crystallites were deposited onto HOPG by a potentiodynamic scan from 0.4 to $-0.4 \mathrm{~V}$ and finally scanning up to $0.1 \mathrm{~V}$ at $2 \mathrm{mV} \mathrm{s}^{-1}$, in $1.0 \mathrm{mM} \mathrm{AgClO}{ }_{4}+0.1 \mathrm{M} \mathrm{KClO}_{4}$ (pH 3.0) solution. (*) Main Raman band from $\mathrm{ClO}_{4}{ }^{-}$ions. (c) Molecular structure orientation during adsorption of $\mathrm{Pic}^{-}$species on the silver crystallite surface.

with the Raman spectra in solution and from the literature. In addition, frequencies of the main vibrational modes, given between parentheses, were calculated by DFT taking into account the interaction between one silver atom and the most stable molecular structure at each $\mathrm{pH}$ (data given in Figure S3 and Table S3 in the Supporting Information).

Both ex situ SERS spectra of PA and Ag-PA solutions at $\mathrm{pH}$ 0.3 show common bands with different intensities at 933, 1580, and $240 \mathrm{~cm}^{-1}$, which were assigned to the $\mathrm{Cl}-\mathrm{O}$ stretching vibration of the perchlorate ion, ${ }^{38}$ the $\mathrm{G}$ mode from HOPG substrate produced by the silver crystallites, ${ }^{40,41}$ and the $\mathrm{Ag}-\mathrm{O}$ bond stretching mode, ${ }^{14,42,43}$ respectively. The signal at low frequencies can be related to the silver surface oxidation or to the $\mathrm{ClO}_{4}{ }^{-}$adsorption on the crystallites.

In Figure 2, there are no noticeable SERS signals from the additive in the spectra at $\mathrm{pH} 0.3$, which is indicative that the 


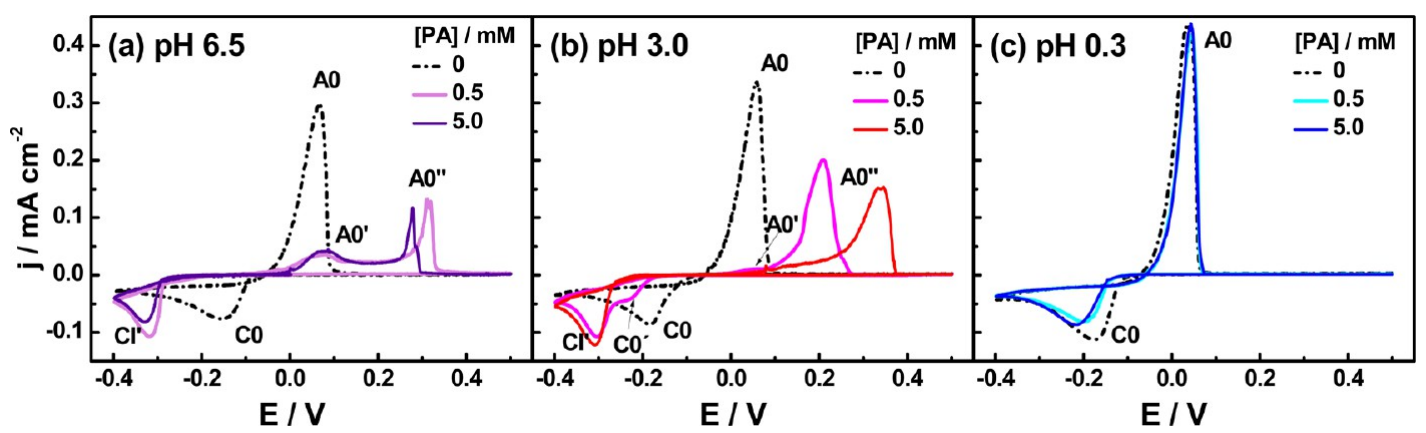

Figure 3. Potentiodynamic $j / E$ profiles of silver deposition and dissolution onto $\mathrm{HOPG}$ electrodes in $0.1 \mathrm{M} \mathrm{KClO}_{4}$ or $0.5 \mathrm{M} \mathrm{HClO}_{4}$ solutions with 1 $\mathrm{mM} \mathrm{AgClO}+4 \mathrm{mM}$ PA $(0<x<5.0)$ at (a) $\mathrm{pH} 6.5$; (b) 3.0; and (c) 0.3. Scan rate: $5 \mathrm{mV} \mathrm{s}^{-1}$.

$\mathrm{H}_{2} \mathrm{Pic}^{+}$cation (relevant species in solution) is not adsorbed on silver. In contrast, at $\mathrm{pH} 3.0$ and 6.5 , characteristic signals of the adsorbed PA species are observed in both ex situ SERS spectra, besides the signals from the $\mathrm{ClO}_{4}{ }^{-}$ions and the HOPG surface. It is noticeable that in the presence of PA or silver complexes (Figure 2a and $\mathrm{b}$ ) at $\mathrm{pH} 3.0$ and 6.5 the SERS signals of the Pic $^{-}$at $845,1052,1384,1441$, and $1474 \mathrm{~cm}^{-1}$ (Table 1) were clearly identified. These results could be explained by considering that picolinate species form surface complexes $\left(\mathbf{A g}^{\mathbf{0}}-\mathbf{P i c}^{-}\right)$with the silver crystallites, as was demonstrated by other authors. ${ }^{44}$ Evidence of the $\mathbf{A g}^{\mathbf{0}}-\mathbf{P i c}^{-}$formation is given by the analysis of the most intense SERS signals in conjunction with DFT calculations (Figure S3 and Tables S3 and S4 in the Supporting Information). One particular characteristic noted in the SERS spectra at both $\mathrm{pH}$ 's was the wavenumber change of the trigonal ring breathing mode $\left(\nu_{12}\right)$, produced when the molecule was adsorbed, i.e., from $1003 \mathrm{~cm}^{-1}$ (Raman spectra of Pic $^{-}$solution) to $1014 \mathrm{~cm}^{-1}$ (in the SERS spectra). This feature is due to the nitrogen of the pyridine ring interacting directly with the crystallites. ${ }^{19}$ Similar results concerning pyridinecarboxylic acids adsorption on electrochemically activated silver electrodes have been published. ${ }^{12,20,21,37}$ Thus, ex situ SERS spectra show that PA molecules undergo deprotonation upon adsorption, the $\mathbf{P i c}^{-}$anion being the stable adsorbate species, even for the solution at $\mathrm{pH} 3.0$ where the HPic zwitterion predominates (Table 2). Moreover, the intense signal at around $240 \mathrm{~cm}^{-1}$ attributed to both $\mathrm{Ag}-\mathrm{N}$ and $\mathrm{Ag}-\mathrm{O}$ stretching contributions supports the validity of a chemisorption process for the $\mathrm{Pic}^{-}$anion on silver, via both the ring nitrogen and carboxylate groups as well as the feasible oxidation of crystallites. ${ }^{14,42,43}$

On the other hand, analysis of SERS spectra taking into account the specific surface selection rules, where a preferential intensification is observed for vibrational modes with components perpendicular to the surface, allowed us to determine the adsorption geometry of molecules on the surface. ${ }^{45,46}$ In particular, changes in the relative intensity for the trigonal ring breathing mode (at around $1014 \mathrm{~cm}^{-1}$ ) can be an important criterion for determining the orientation of aromatic molecules. ${ }^{47}$ Since this signal is the most intense in SERS spectra at $\mathrm{pH} 3.0$ and 6.5 , it is possible to infer that the additive molecules are perpendicularly adsorbed on the silver surface. Furthermore, by considering the strong intensities of the symmetric stretching mode of the $\mathrm{COO}^{-}$group (at $1384 \mathrm{~cm}^{-1}$ ) and the bending mode $\delta(\mathrm{OCO})$ at $845 \mathrm{~cm}^{-1}$, it is suggested that the $\mathrm{Pic}^{-}$species are positioned by the carboxylate group on the silver crystallites. Other features observed in the ex situ spectra are the presence of $\mathrm{C}-\mathrm{N}$ stretching bands (at 1441 and $1474 \mathrm{~cm}^{-1}$ ) and the absence of typical bands of the protonated pyridinic ring
(1039 and $\left.1625 \mathrm{~cm}^{-1}\right) .^{22}$ Therefore, it is possible to conclude that $\mathrm{Pic}^{-}$species (at $\mathrm{pH} 3.0$ and 6.5) are adsorbed perpendicularly to the SERS active surface through both functional groups (i.e., the pyridinic-nitrogen and the carboxylate), as represented in Figure $2 c$, in agreement with published results. ${ }^{12,23}$

As previously mentioned the ex situ SERS spectra for complexes and PA molecule adsorbates at $\mathrm{pH} 3.0$ and 6.5 show the same signals with different relative intensities. These results indicate that the adsorbed species is the same (the picolinate anion), in the presence or absence of $\mathrm{Ag}^{+}$ions, and when added to the $\mathrm{Pic}^{-}$species forms surface complexes with the $\mathrm{Ag}$ atoms, as shown in Figure S3 in the Supporting Information., 8,

3.4. In Situ SERS Spectra of PA during Silver Electrodeposition. Adsorption of picolinic acid at the electrode/electrolyte interface and its influence on the silver electrodeposition process were studied by spectroelectrochemical experiments carried out in solutions of different $\mathrm{pH}$ and $\mathrm{PA}$ concentrations. Potentiodynamic scans from 0.4 to $-0.4 \mathrm{~V}$ returning up to $0.5 \mathrm{~V}$ at $1 \mathrm{mV} \mathrm{s}^{-1}$ in $1.0 \mathrm{mM} \mathrm{AgClO}_{4}+x \mathrm{mM}$ picolinic acid $(0<x<5.0)$, in $0.5 \mathrm{M} \mathrm{HClO}_{4}$ ( $\left.\mathrm{pH} 0.3\right)$ or in $0.1 \mathrm{M} \mathrm{KClO}_{4}(\mathrm{pH} 3.0$ and 6.5) solutions, were applied to the HOPG electrode, and the Raman scattering was simultaneously recorded. The following analysis of the spectroelectrochemical results was performed separately according to the $\mathrm{pH}$ of the solution.

3.4.1. At $p H$ 6.5. Figure $3 a$ shows the potentiodynamic $j / E$ profiles of the HOPG electrodes in solutions containing different concentrations of $\mathrm{PA}$ at $\mathrm{pH} 6.5$ and $5 \mathrm{mV} \mathrm{s}^{-1}$ scan rate. When the additive is absent (black dotted curve), a cathodic peak $(\mathbf{C O})$ at $-0.15 \mathrm{~V}$ was observed, which corresponds to the electroreduction of $\mathrm{Ag}^{+}$ions (reaction 5).

$$
\mathrm{Ag}^{+}+\mathrm{e}^{-} \rightarrow \mathrm{Ag}^{0}
$$

On reversing the potential scan at $-0.4 \mathrm{~V}$, the silver deposition continues until $-0.05 \mathrm{~V}$ (cathodic current density nonzero), and the characteristic peak (A0) for silver stripping at $0.065 \mathrm{~V}$ was defined. The intersection between the cathodic and anodic curves at around $-0.10 \mathrm{~V}$ together with the peak potentials for deposition and dissolution are indicative of a 3-D nucleation and growth process for silver electrodeposition, with the charge transfer step not being reversible. ${ }^{27}$

As seen in Figure 3, the presence of PA produces noticeable changes in the potentiodynamic behavior of silver deposition onto the HOPG electrodes. At $\mathrm{pH} \mathrm{6.5,} \mathrm{the} \mathrm{shifting} \mathrm{of} \mathrm{the}$ cathodic peak $\left(\mathbf{C I}^{\prime}\right)$ to more negative potentials along with two anodic contributions $\left(\mathbf{A 0}^{\prime}\right.$ and $\left.\mathbf{A 0}^{\prime \prime}\right)$ for silver stripping are highlighted (light and dark purple curves). The first feature is produced by adsorption of additive molecules on the electrode 

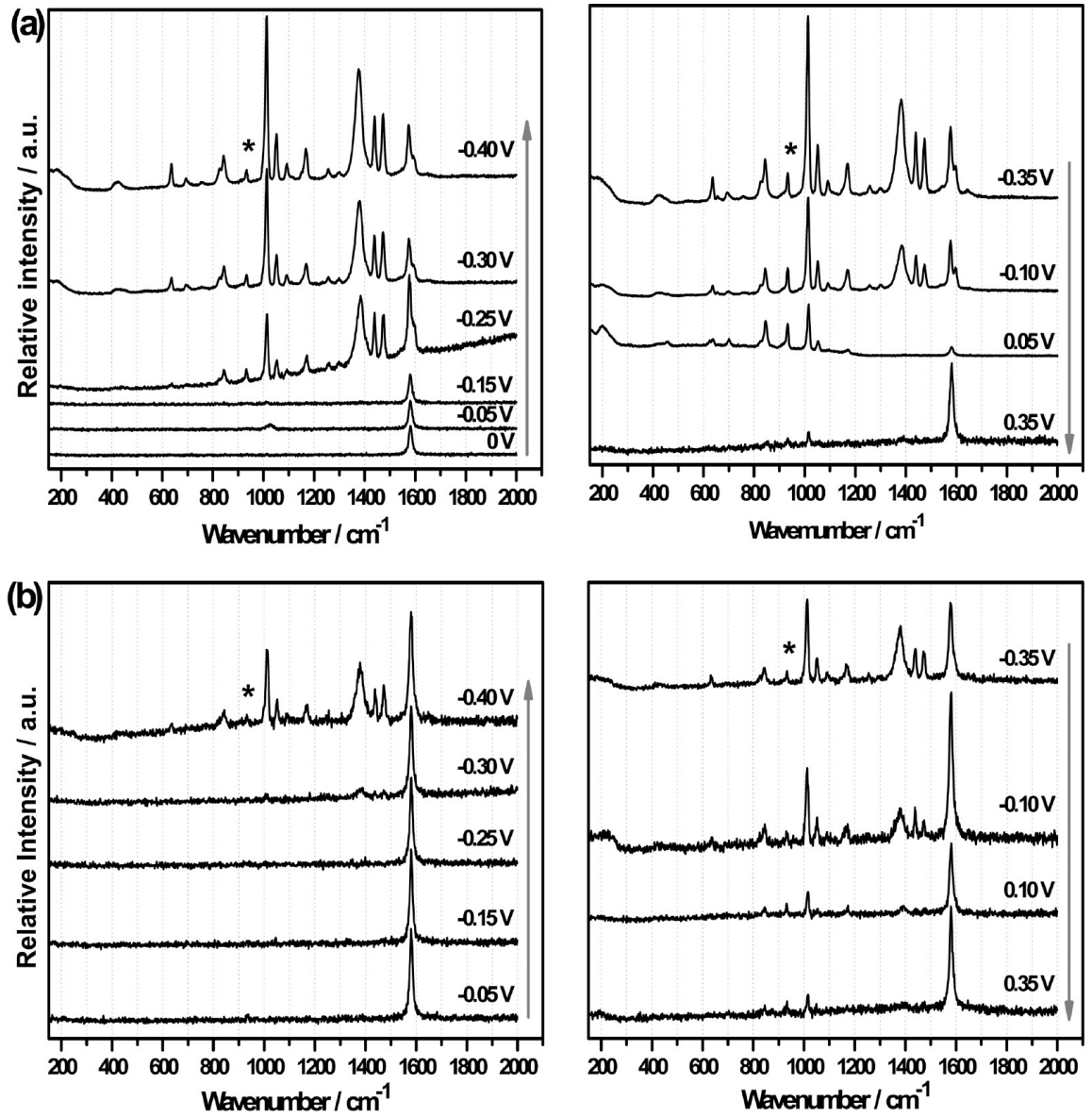

Figure 4. In situ SERS spectra at different potentials during potentiodynamic silver deposition and dissolution onto HOPG electrodes in $0.1 \mathrm{M}$ $\mathrm{KClO}_{4}+1 \mathrm{mM} \mathrm{AgClO}_{4}+x \mathrm{mM} \mathrm{PA}$, where $x=0.5$ (a) or $x=5.0(\mathrm{~b})$ at $\mathrm{pH}$ 6.5. Scan rate: $1 \mathrm{mV} \mathrm{s}^{-1}$. (*) Main Raman band from $\mathrm{ClO}_{4}^{-}$ions.

surface with the peak $\mathbf{C I}^{\prime}$ being assigned to the electroreduction of silver complexes (reaction 6). ${ }^{15}$ This assignment is perfectly coherent since the complexes in solution presented high stabilities and a higher electroreduction overpotential than that required for uncomplexed $\mathrm{Ag}^{+}$ions. By considering the stability constant $\mathrm{K}_{[A g(P i c)]}(\mathrm{pH} 6.5)=800 \pm 100 \mathrm{M}^{-1}$ for the $[\mathrm{Ag}($ Pic $)]$ complexes (reaction 4), it is possible to establish that for $5.0 \mathrm{mM}$ of PA many $\mathrm{Ag}^{+}$ions are complexed with $\mathrm{Pic}^{-}$ligands in solution, while for $0.5 \mathrm{mM} \mathrm{PA}+1.0 \mathrm{mM} \mathrm{Ag}^{+}$solutions, only about $20 \%$ of $\mathrm{Ag}^{+}$ions form complexes (Table 2). Despite the presence of two different electroactive species in solution $\mathrm{C}^{+}$ and $[\mathbf{A g}(\mathbf{P i c})])$, a single broad peak $\mathbf{C I}^{\prime}$ of deposition was observed (Figure 3a). Therefore, its assignment corresponds to the simultaneous reduction of both species (reactions 5 and 6).

$$
[\boldsymbol{A g}(\boldsymbol{P i c})]+\mathrm{e}^{-} \rightarrow \mathrm{Ag}^{0}+\boldsymbol{P i c}^{-}
$$

As mentioned above, the observed shifting of the $\mathbf{C I}^{\prime}$ peak potential was produced by the adsorption of the additive molecules onto the HOPG surface. If we consider that adsorption of PA may also occur on the Ag growing crystallites, then the inhibition of the $\mathbf{C I}^{\prime}$ current density for increasing PA concentration (Figure 3a) can also be explained.

To confirm this reaction mechanism, the chemical identification of the adsorbed species was performed by following the silver deposition process with simultaneous recording of the surface spectra. ${ }^{49}$ In situ SERS spectra recorded at different potentials during the silver potentiodynamic electrodeposition at $1 \mathrm{mV} \mathrm{s}^{-1}$, in the presence of 0.5 and
$5.0 \mathrm{mM}$ of picolinic acid at $\mathrm{pH} 6.5$, are shown in Figure 4. The SERS spectra contain a band at $932 \mathrm{~cm}^{-1}$ from the $\mathrm{Cl}-\mathrm{O}$ stretching vibration of $\mathrm{ClO}_{4}{ }^{-}$ions from the supporting electrolyte (marked with $*),{ }^{38}$ which was employed as the internal standard for normalization of the surface spectra. It is well-known that the analysis of absolute intensities of the adsorbate SERS signals allows the surface concentration of the molecules to be estimated. ${ }^{49}$ However, in practice, quantification of the adsorbed species on the crystallites is very complicated to achieve because the number of active sites for enhancement of the Raman scattering is being constantly modified throughout the experiment, in an equivalent way to variation of the silver surface roughness. ${ }^{50}$

When the PA concentration is $0.5 \mathrm{mM}$, the SERS signals from the additive begin to be detected from $-0.05 \mathrm{~V}$ (Figure $4 \mathrm{a}$ ), although the cathodic current in the voltammogram starts to be noticed at $-0.25 \mathrm{~V}$ (Figure 3a). The increase in the relative Raman intensity with applied overpotential is directly related to the type of morphology and size of the silver crystallites obtained at the different potentials, which are optimal for producing the SERS effect even for the G band of the HOPG substrate at $1579 \mathrm{~cm}^{-1}$. Increasing the additive concentration to $5.0 \mathrm{mM}$ resulted in the SERS spectra of the adsorbed molecules being detected at more negative potentials (Figure $4 \mathrm{~b}$ ) and SERS intensity lower than that for $0.5 \mathrm{mM}$. This effect is directly related to the inhibition in the silver electrodeposition process observed in the voltammograms (large deposition overpotential and decrease of the cathodic current), due to the large quantity of Pic $^{-}$anion adsorbed on both HOPG and silver surfaces. 

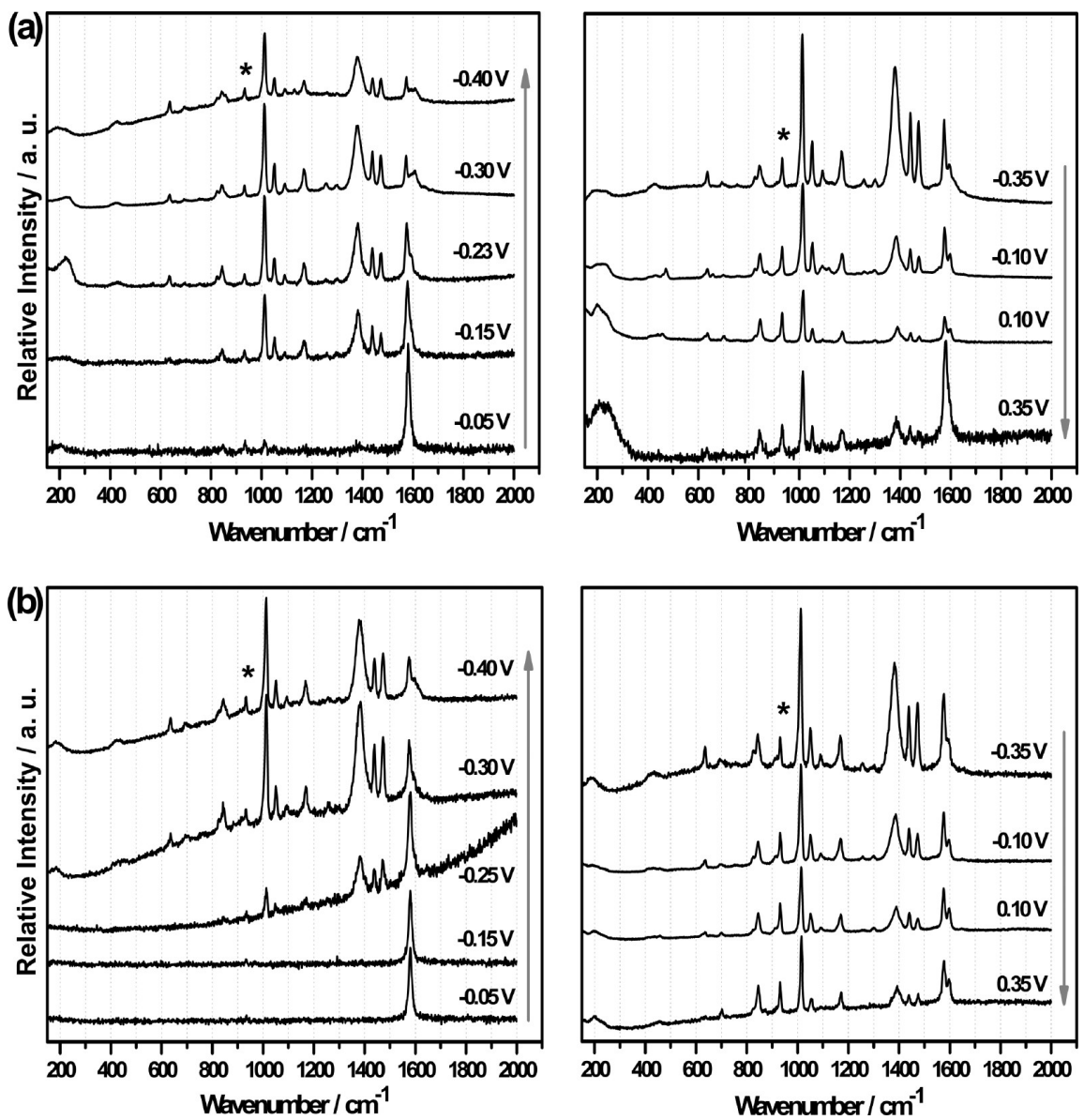

Figure 5. In situ SERS spectra at different potentials during silver potentiodynamic deposition and dissolution onto HOPG electrodes in $0.1 \mathrm{M}$ $\mathrm{KClO}_{4}+1 \mathrm{mM} \mathrm{AgClO}_{4}+x \mathrm{mM} \mathrm{PA}$, where $x=0.5$ (a) or $x=5.0(\mathrm{~b})$ at $\mathrm{pH}$ 3.0. Scan rate: $1 \mathrm{mV} \mathrm{s}^{-1}$. (*) Main Raman band from $\mathrm{ClO}_{4}{ }^{-}$ions.

The most intense SERS bands in the spectra recorded at potentials more negative than $-0.05 \mathrm{~V}$ were at $844,1052,1384$, 1441 , and $1474 \mathrm{~cm}^{-1}$, which correspond to the picolinate anion adsorbed species with the geometry shown in Figure 2c, with both functional groups interacting directly with the surface. Furthermore, the relative intensities did not reveal significant changes when the applied potential and the PA concentration were modified. As a consequence, its geometry of adsorption may be assumed to be invariant.

The enhancement of the $\mathbf{P i c}^{-}$bands was also noticeable when the potential scan was reversed, even after reaching the dissolution potential of the crystallites (at around $0.1 \mathrm{~V}$ ). This feature indicates that silver dissolution was not complete even at anodic potentials where SERS-active silver clusters remain on the HOPG surface. Moreover, the increase or decrease in the intensity of the $\mathrm{ClO}_{4}^{-}$band at $932 \mathrm{~cm}^{-1}$ occurred in a fashion similar to that of the PA spectrum throughout the spectroelectrochemical experiment, indicating coadsorption of $\mathrm{ClO}_{4}{ }^{-}$ions with the organic additive. Because the coadsorption of $\mathrm{ClO}_{4}{ }^{-}$involves a very weak interaction with the silver surface, the wavenumber of the $\nu_{s}\left(\mathrm{ClO}_{4}^{-}\right)$is the same as in the bulk solution, thus the band at 932 $\mathrm{cm}^{-1}$ derives from both the coadsorbed $\mathrm{ClO}_{4}^{-}$ions on the silver surface and the ions present in the electrolyte. ${ }^{51}$

3.4.2. At $p H$ 3.0. Figure $3 \mathrm{~b}$ shows the $j / E$ potentiodynamic behavior of $\mathrm{HOPG}$ in $0.1 \mathrm{M} \mathrm{KClO}_{4}+1.0 \mathrm{mM} \mathrm{AgClO}_{4}$ in the absence or presence of 0.5 or $5.0 \mathrm{mM} \mathrm{PA}$ at $\mathrm{pH} 3.0$, recorded at a scan rate of $5 \mathrm{mV} \mathrm{s}^{-1}$. The voltammetric response (pink and red curves) shows a shifting of the onset potential for silver deposition together with a displacement of the $\mathbf{C I}^{\prime}$ potential with respect to that obtained in the absence of the additive (C0), similar to that observed at $\mathrm{pH}$ 6.5. However, in this case, an additional cathodic shoulder $\mathbf{C O}^{\prime}$ at around $-0.25 \mathrm{~V}$ was evidenced. This feature that stands more noticeable when the scan rate and the concentration ratio $[\mathrm{PA}] /\left[\mathrm{Ag}^{+}\right]$are low can be clearly associated with the $\mathrm{Ag}^{+}$ions electroreduction (reaction 5) at low overpotentials.

Raman spectra recorded during the potential scan for silver deposition and dissolution at $\mathrm{pH} 3.0$, in the presence of $0.5 \mathrm{mM}$ (a) and $5.0 \mathrm{mM}$ PA (b), are shown in Figure 5. The changes in the relative intensities of the Raman bands produced by electrode potential modification were similar for solutions at $\mathrm{pH} 6.5$ and 3.0, in spite of the voltammograms being different (Figure 3). In general, the in situ experiments at $\mathrm{pH} 3.0$ show the same bands as those observed for ex situ configurations (Section 3.3) obtained by deposition of a drop of PA or PA + $\mathrm{Ag}^{+}$ions solutions on silver deposited structures (Figures 2 and 5). Thus, the species present at the interface at $\mathrm{pH} 3.0$ were the same as those at $\mathrm{pH}$ 6.5, i.e., the $\mathrm{Pic}^{-}$anion and/or $[\mathrm{Ag}(\mathbf{P i c})]$ complexes, with both functional groups interacting with the silver surface.

During the positive potential scan, silver deposition continued up to $-0.11 \mathrm{~V}$, and the SERS signal intensity increased; however, when dissolution of the crystallites began, the intensity of the whole spectra diminished. It was noticeable that at $0.35 \mathrm{~V}$ and $0.5 \mathrm{mM}$ PA (Figure 5a), when the dissolution current was negligible, the SERS spectrum presented a very 

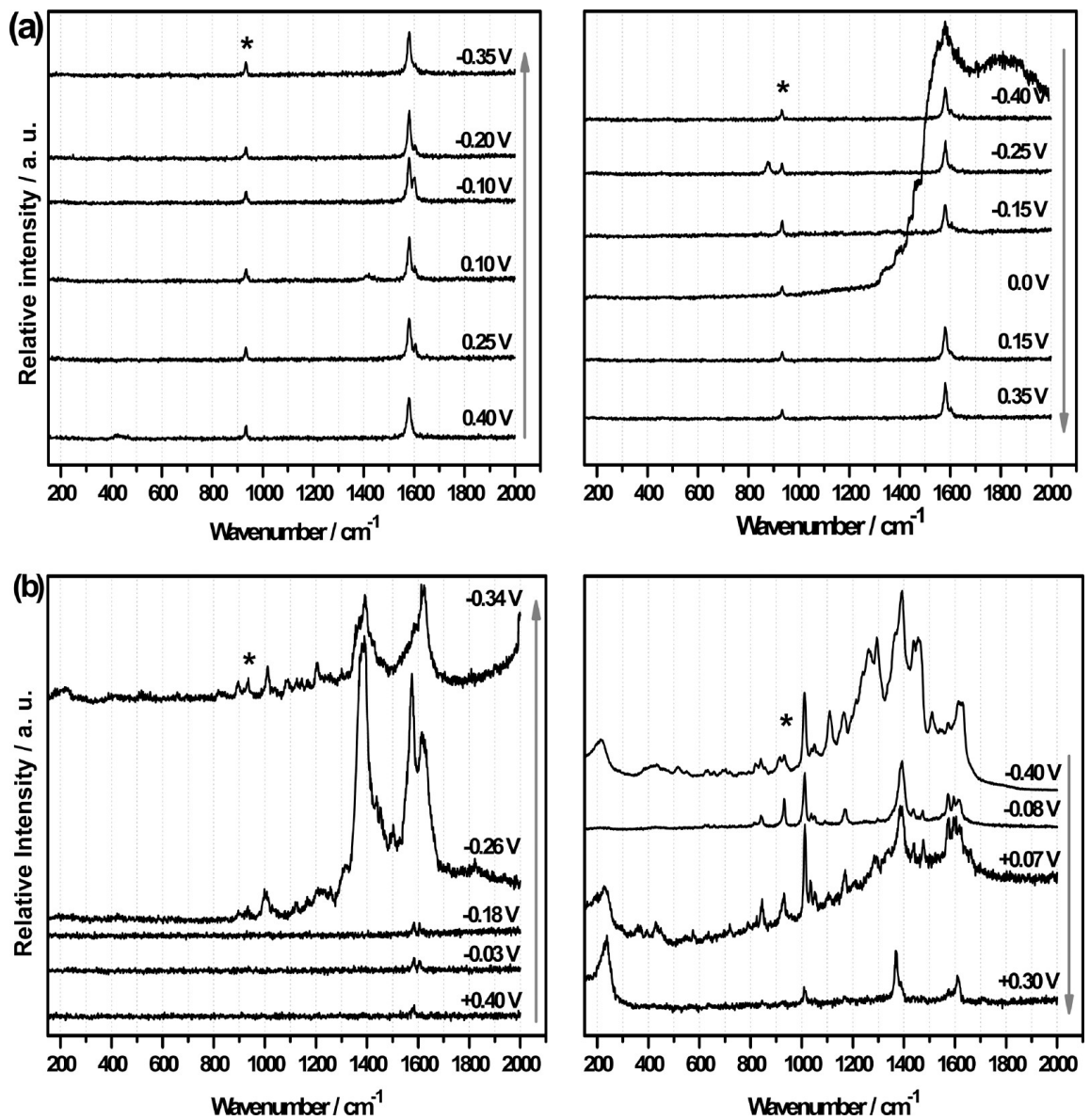

Figure 6. In situ SERS spectra at different potentials during silver potentiodynamic deposition and dissolution onto HOPG electrodes in $0.5 \mathrm{M}$ $\mathrm{HClO}_{4}+1 \mathrm{mM} \mathrm{AgClO}_{4}+x \mathrm{mM} \mathrm{PA}$, where $x=0.5$ (a) or $x=5.0$ (b) at $\mathrm{pH} 0.3$. Scan rate: $1 \mathrm{mV} \mathrm{s}^{-1}$. (*) Main Raman band from $\mathrm{ClO}_{4}^{-}$ions.

intense and broad signal at $240 \mathrm{~cm}^{-1}$ associated with the $\mathrm{Ag}-\mathrm{N}$ or $\mathrm{Ag}-\mathrm{O}$ interaction of the PA molecule with the silver surface and/or due to the feasible crystallites oxidation. ${ }^{12,23}$ Within the experimental setup and the mechanism hypothesized, it is not possible to decide whether the band at $240 \mathrm{~cm}^{-1}$ is associated with $\mathrm{Ag}-\mathrm{N}$ or $\mathrm{Ag}-\mathrm{O}$ interactions; however, it is possible to observe that this band is present in the SERS spectra that indicates specific interaction between the picolinic acid species and Ag crystallites. ${ }^{12,23}$

Considering the equilibrium concentrations of the PA species (Table 2), the analysis of different PA analytical concentrations at $\mathrm{pH} 3.0$ indicates that more than $90 \%$ of $\mathrm{Ag}^{+}$ions are uncomplexed and that the concentration of the $\left[\mathrm{Ag}(\mathrm{HPic})^{+}\right]$ complexes is negligible. For this reason, the $\mathbf{C I}^{\prime}$ peak should not be associated with the reduction reaction of this species. Furthermore, the quantities of both the $\left[\mathrm{Ag}(\mathbf{H P i c})^{+}\right]$and $[\mathrm{Ag}(\mathrm{Pic})]$ complexes present in solution were quite similar. However, the Raman spectrum corresponded to only the $\mathbf{P i c}^{-}$ anion and $[\mathrm{Ag}(\mathrm{Pic})]$ complexes, which implies that the effective value of $\mathrm{p} K_{\mathrm{a}}$ in the electrode/electrolyte interface was lower than in the solution bulk. This effect may have been due to several factors: First, the concentration of $\mathrm{H}^{+}$ions was expected to be very low in the vicinity of the metal surface relative to the bulk solution, due to the surface being positively charged (the potential of zero charge was $-0.71 \mathrm{~V}) .{ }^{52}$ Second, the effective $\mathrm{p} K_{\mathrm{a}}$ was lower as a result of an increased stability of the ionic species (anion) to the charge-neutral (zwitterion), due to a Coulombic attraction type "image charge" to the surface.
Furthermore, the surface complexes $\mathrm{Ag}^{0}-\left(\mathrm{Pic}^{-}\right)$were more stable because the $\mathrm{Ag}^{0}$ interacted with the anion through two sites (functional groups), the pyridinic-nitrogen and $\mathrm{COO}^{-}$, while the interaction with the zwitterion was only by $\mathrm{COO}^{-}$ (see Figure S3 and Table S3 in the Supporting Information). Therefore, the anion was preferentially adsorbed on the silver crystallites with the chemical equilibrium on the electrode surface being different from that occurring in the bulk solution. ${ }^{53-55}$ Thus, we can conclude that the current peak $\mathbf{C I}^{\prime}$ observed at $\mathrm{pH} 3.0$ was associated with the reduction of $[\mathrm{Ag}(\mathrm{Pic})]$ complexes (reaction 6).

3.4.3. At $p H$ 0.3. In the presence of the additive, no significant changes were evidenced in the potentiodynamic profiles at $\mathrm{pH} 0.3$ (Figure 3c). Only a small shifting on the electrodeposition potential (CO current peak) to more negative values, with the decrease in the cathodic charge, was observed, a feature that depends on the PA concentration. Furthermore, the absence of any other current peak in the voltammograms shows that the cationic species $\mathrm{H}_{2} \mathrm{Pic}^{+}$were not coordinated to $\mathrm{Ag}^{+}$ions in solution, and as mentioned above, they were also not adsorbed on the HOPG surface. Therefore, the observed slight reduction of the deposition charge is related to the HPic adsorption on both the HOPG and silver surfaces, mainly because its content in solution is not negligible (Table 2).

Figure 6 shows the in situ Raman spectra recorded during the potentiodynamic scan in solutions at $\mathrm{pH}$ 0.3. Although deposition and dissolution of silver crystallites occur on the substrate (Figure 3c), the signals from the PA vibrational 
modes were not observed in the spectra at different potentials for $0.5 \mathrm{mM}$ PA (Figure 6a). Moreover, the HOPG band $\left(1579 \mathrm{~cm}^{-1}\right)$ which remained constant in intensity, the band from surface defects $\left(1390 \mathrm{~cm}^{-1}\right)$ which was absent, and the increase in the baseline at $0.0 \mathrm{~V}$ during silver dissolution were the only changes observed. These results show that the deposited silver crystallites did not produce any Raman signal enhancement of HOPG, and the $\mathrm{H}_{2} \mathrm{Pic}^{+}$species are not adsorbed on its surface, in agreement with the electrochemical behavior.

Notably, when the PA concentration was increased to $5 \mathrm{mM}$ a potential dependence of the spectra (Figure 6b) was observed, mainly given by an increase in the SERS spectrum of PA at around $-0.26 \mathrm{~V}$. This effect seems to contradict our previous results (Figures 2 and 6a), where it was determined that the $\mathbf{H}_{2} \mathrm{Pic}^{+}$species did not form complexes in solution with $\mathrm{Ag}^{+}$ions, and they were not adsorbed on the electrode surface. However, considering the species distribution curve for the PA acid-base equilibrium (Figure S1 in the Supporting Information and Table 2), when the PA concentration was $5 \mathrm{mM}, 16 \%$ of zwitterion was present in the solution bulk, which may thus be adsorbed onto the silver surface. Moreover, taking into account the cation and zwitterion species at $\mathrm{pH} 0.3$, it should be noted that the SERS evidence indicates that only HPic was adsorbed on the silver structures, which is due to the available functional group. Thus, by decreasing the analytical PA concentration, the amount of zwitterion in solution reached a value below the detection limit for the SER spectroscopy with the experimental setup used (Table 2 and Figure 6a). However, signals in Figure $6 \mathrm{~b}$ do not fully correspond to the adsorbed $\mathrm{Pic}^{-}$spectra as in the ex situ (Figure 2) and in situ (Figure 5) experiments, as shown in Figure 7.

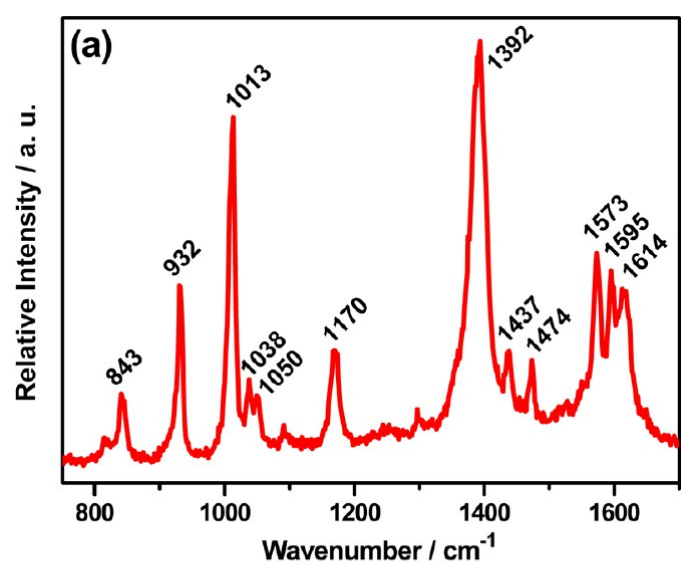

(b)

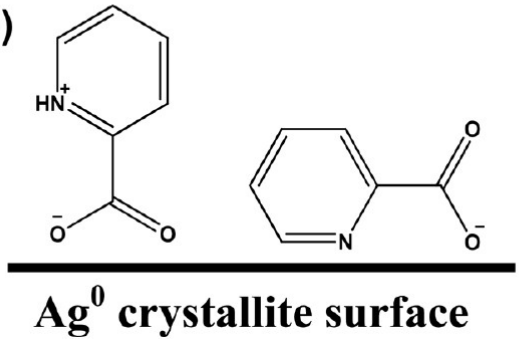

Figure 7. (a) In situ SERS spectrum at $-0.08 \mathrm{~V}$ during silver potentiodynamic deposition and dissolution onto HOPG electrodes in $0.5 \mathrm{M} \mathrm{HClO}_{4}+1 \mathrm{mM} \mathrm{AgClO}+5 \mathrm{mM} \mathrm{PA}$ at pH 0.3. (b) Scheme of the molecular orientations for $\mathrm{HPic}$ and $\mathrm{Pic}^{-}$species adsorption on the silver crystallite surface, respectively.
In the spectrum of Figure 7, it is possible to identify two different species adsorbed onto the silver crystallites: anion and zwitterion. Adsorbed $\mathrm{Pic}^{-}$species were characterized by the vibrational modes of the aromatic ring $\nu 1, \nu 19 \mathrm{~b}, \nu 19 \mathrm{a}$, and $\nu 8 \mathrm{~b}$, associated with the SERS spectra bands at 1050, 1437, 1474, and $1595 \mathrm{~cm}^{-1}$, respectively (Table 1), and the adsorption of HPic species was determined by the signals at $1038 \mathrm{~cm}^{-1}(\nu 1)$ and $1614 \mathrm{~cm}^{-1}(\nu 8 \mathrm{a})$, typical of the protonated pyridinic ring (Table 1). Similar results were also reported for PA adsorption in acidic solutions $(\mathrm{pH}<1)$ on silver and copper electrodes ${ }^{12,19,22}$ and silver colloids. ${ }^{56}$ The strong intensification of the signal at $1013 \mathrm{~cm}^{-1}(\nu 12$, trigonal ring breathing) implies that the adsorbed molecule was perpendicular to the surface. ${ }^{12,47}$ However, as the zwitterion species HPic had the protonated nitrogen in the pyridinic ring, the adsorption geometry was not the same as that for the anion $\mathrm{Pic}^{-}$given in Figure 2c. Therefore, it is proposed that at $\mathrm{pH} 0.3$ both $\mathbf{H P i c}$ and $\mathbf{P i c}^{-}$ species interacted with the silver surface, the former through the carboxylate group and the latter by both functional groups with the adsorption configuration of the pyridine ring perpendicular to the surface (Figures $7 \mathrm{~b}$ and $\mathrm{S} 3$ in the Supporting Information).

3.5. Morphological Characterization of Silver Crystallites. The morphological characteristics of the deposited silver crystallites were established by SEM micrographs. SEM images in Figure 8 were obtained after removing the electrodes from the cell at various stages of the voltammogram during the silver electrodeposition in solutions of different compositions. After deposition at $-0.4 \mathrm{~V}$ in the absence of PA (at $\mathrm{pH} 3.0$ ), SEM image $8 \mathrm{a}$ reveals large silver structures containing dendritic branches. The ramifications are flat and smooth (thickness of approximately $100 \mathrm{~nm}$ ) with dimensions varying between 300 and $700 \mathrm{~nm}$. In addition, various small structures without any sharp features on the HOPG substrate are also observed.

Silver crystallites deposited in the presence of PA at $\mathrm{pH} 0.3$, as expected from spectroscopic and voltammetric measurements, were similar to those obtained without additive, although being slightly smaller and containing minor sharp branches. On the other hand, when the electrolyte $\mathrm{pH}$ was 3.0, the morphology of the crystallites was markedly different as they were smaller and globular, with flower-like structures composed of nanosheets with a thickness of around $20 \mathrm{~nm}$. At $-0.4 \mathrm{~V}$, these highly nanobranched silver structures conformed by intercalated flat flakes have diverse sizes between 0.5 and 0.9 $\mu \mathrm{m}$. At $\mathrm{pH} 6.5$, the structures obtained were morphologically similar to those obtained at $\mathrm{pH} 3.0$, but they were smaller (up to $500 \mathrm{~nm}$ in diameter) in agreement with the electrochemical results, where we observed that the deposition charge was also diminished (Figure 3).

When the potentiodynamic scan was reversed, the electrodeposition of silver continued on the substrate surface, but there were no great changes in the morphology or size of the structures up to $-0.1 \mathrm{~V}$ in the absence of PA (Figure $8 \mathrm{~b}$ ). At $\mathrm{pH} 0.3$ and $5 \mathrm{mM}$ PA, the silver dissolution was obvious at this potential by the loss of the dendritic morphology of the crystallites (Figure $8 \mathrm{~b}$ ). Complete dissolution of crystals was observed at potentials greater than $0 \mathrm{~V}$.

The quantity, polydispersion degree, and average size of the silver structures on the HOPG were diminished when the potential scan was continued to potentials higher than $-0.1 \mathrm{~V}$ for $5 \mathrm{mM}$ PA solutions at $\mathrm{pH} 3.0$ and 6.5. By following the potential scan up to $0.1 \mathrm{~V}$, i.e., after the $\mathbf{A \mathbf { 0 } ^ { \prime }}$ peak (Figure 3), the crystallites are smaller, and the dispersion in size is higher 


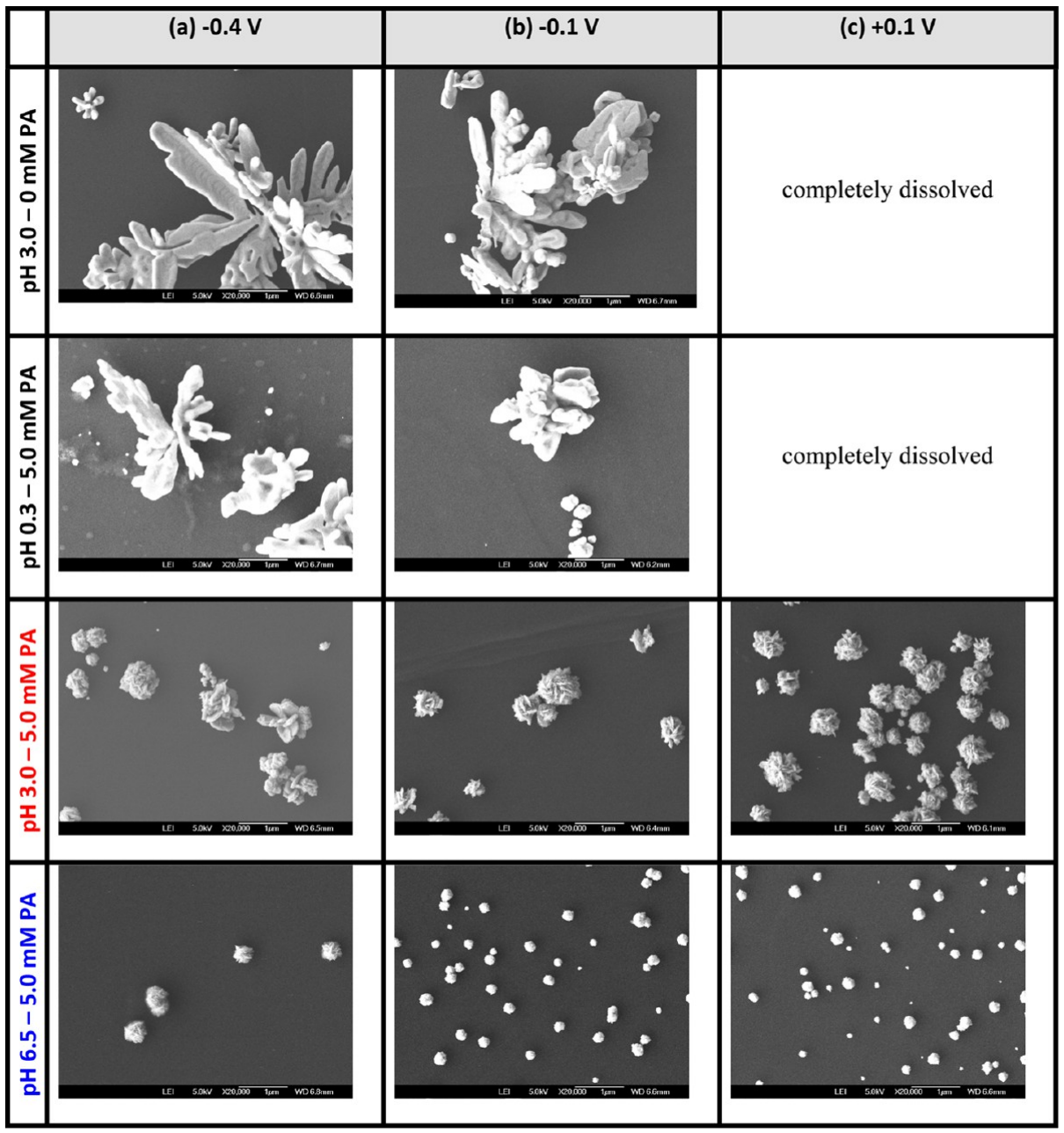

Figure 8. SEM micrographs of the HOPG electrode after silver deposition by potentiodynamic scan up to different potentials (Figure 3 ) in $0.1 \mathrm{M}$ $\mathrm{KClO}_{4}+1.0 \mathrm{mM} \mathrm{AgClO}_{4}$ solutions at $\mathrm{pH} 3.0$ or in $0.5 \mathrm{M} \mathrm{HClO}_{4}+1 \mathrm{mM} \mathrm{AgClO}_{4}+5 \mathrm{mM} \mathrm{PA}(\mathrm{pH} 0.3)$ and $0.1 \mathrm{M} \mathrm{KClO}_{4}+1 \mathrm{mM} \mathrm{AgClO}{ }_{4}+$ $5.0 \mathrm{mM}$ PA (pH 3.0 and 6.5). Scan rate: $2 \mathrm{mV} \mathrm{s}^{-1}$.

than that obtained at $-0.1 \mathrm{~V}$, due to a partial deposit dissolution. On the basis of these results, we can establish that the influence of PA addition on the structure morphology depends on the solution $\mathrm{pH}$. Also, it is important to note that the cation species of PA (at $\mathrm{pH} 0.3$ ) did not produce any significant modifications on the deposited structures, whereas the HPic and $\mathrm{Pic}^{-}$species caused a drastic inhibition of the particle growth, with a resulting smaller range in size dispersion. The change in morphology of Ag deposits could have been caused by one of the following effects: (i) PA species forming complexes with $\mathrm{Ag}^{+}$ions in solution, with the deposition reaction potential being shifted to more negative values and (ii) the $\mathrm{Pic}^{-}$species (in excess) partially covering the growing particle surface by adsorption on preferential sites on the crystal, which induced an anisotropic growth.

3.6. Influence of the PA Concentration on SERS Spectra. Figure 9 shows the in situ SERS spectra recorded at $-0.1 \mathrm{~V}$ in solutions containing 0.5 and $5.0 \mathrm{mM} \mathrm{PA}$ at $\mathrm{pH}$ values of $0.3,3.0$, and 6.5 . The intensity scale is indicated in absolute values to be able to compare the magnitude of the SERS intensification by the silver crystallites formed under different conditions. At $\mathrm{pH}$ 0.3, the characteristic SERS signals from the $\mathbf{H P i c}$ and $\mathbf{P i c}^{-}$species were evidenced only when the PA concentration was $5.0 \mathrm{mM}$. This result is consistent with the equilibrium concentrations of the different species, which indicated that the zwitterion predominates at this $\mathrm{pH}$ (Table 2). In contrast, the greatest intensification of the adsorbed species, the Pic $^{-}$anion, at $\mathrm{pH} 3.0$ and 6.5 was observed when the PA concentration was $0.5 \mathrm{mM}$. These results show that the enhancement of Raman scattering obtained was principally due to the morphology of the structures and did not depend on the adsorbed species concentration, at least at $\mathrm{pH} 3.0$ and 6.5 . The most intense signals were found at $\mathrm{pH} 3.0$ which corresponds to the anion species adsorbed on the crystallites.

Flower-like silver crystallites with intercalated flat planes were obtained at $\mathrm{pH} 3.0$ and $0.5 \mathrm{mM} \mathrm{PA}$, with a diameter of approximately $1 \mu \mathrm{m}$ (Figure 9b). The morphology of these structures is adequate to achieve an optimal interaction between the electric field of the incident light and the surface plasmon on the crystallite. ${ }^{57,58}$ We have seen that the presence of the additive as $[\mathbf{A g}(\mathbf{P i c})]$ complexes in the electrode/electrolyte interface promoted this type of growth. Furthermore, the selective adsorption of $\mathrm{Pic}^{-}$and coadsorption of $\mathrm{ClO}_{4}^{-}$ions on the crystal faces of the structures favored the anisotropic growth.

The structure of these flower-like silver particles (Figure 9b) has been demonstrated to be very promising as SERS-active substrates, and the enhancement obtained was related to the high local fields generated on the flake-built structures and in particular to the depth of the gaps between flakes. ${ }^{3}$ The junctions of thin sheets in the nanoflowers resulted in very 


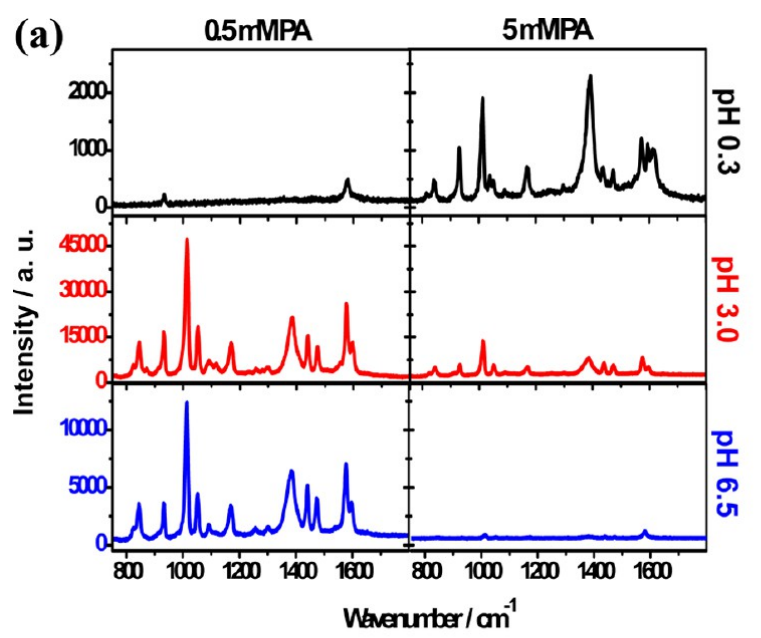

(b)

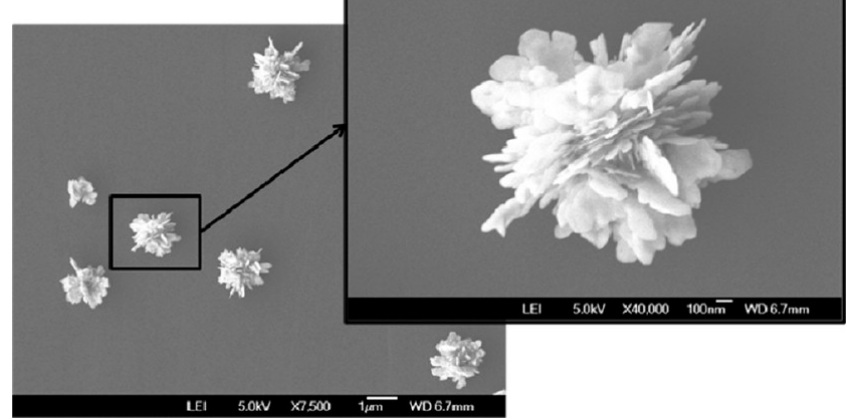

Figure 9. (a) In situ SERS spectra at $-0.1 \mathrm{~V}$ during the potentiodynamic scan at $1 \mathrm{mV} \mathrm{s}^{-1}$ in $1.0 \mathrm{mM} \mathrm{AgClO}{ }_{4}+x \mathrm{mM} \mathrm{PA}(x=0.5$ left; $x=5.0$ right), in $0.5 \mathrm{M} \mathrm{HClO}_{4}$ (pH 0.3) or $0.1 \mathrm{M} \mathrm{KClO}_{4}$ (pH 6.5 and 3.0). (b) SEM micrographs of silver crystallites onto HOPG electrodeposited by a potentiodynamic scan at $-0.1 \mathrm{~V}$ in $1.0 \mathrm{mM} \mathrm{AgClO}_{4}+0.5 \mathrm{mM} \mathrm{PA}+$ $0.1 \mathrm{M} \mathrm{KClO}_{4}$ at $\mathrm{pH}$ 3.0. Scan rate: $2 \mathrm{mV} \mathrm{s}^{-1}$.

small gaps, forming SERS hot spots which were regions that presented a very large enhancement of the local electric fields due to interacting dipoles in the gaps. ${ }^{59,60}$

When the organic adsorbate is present at high concentrations, as in the case of $5 \mathrm{mM}$ PA solutions at $\mathrm{pH} 3.0$ or using alkaline solutions (where the $\mathrm{Pic}^{-}$anion concentration was very high), the growth of silver was inhibited, and the crystallites formed are small and have rough structures. Accordingly, the SERS effect was not favored since these structures had a lower density of SERS active sites.

\section{CONCLUSIONS}

In the present study, we have monitored the silver electrocrystallization process onto HOPG surfaces in the presence of PA. The Raman spectra of PA solutions allowed the identification of cation $\mathrm{H}_{2} \mathrm{Pic}^{+}$, zwitterion $\mathrm{HPic}$, and anion $\mathrm{Pic}^{-}$species, which were predominant in solution at $\mathrm{pH} 0.3$, 3.0 , and 6.5 , respectively.

From the voltamperometric experiments, it was established that the mechanism for silver electrodeposition onto HOPG electrodes in the presence of PA depends on both the $\mathrm{pH}$ and the composition of the solution. When the electrolyte $\mathrm{pH}$ was 0.3 , the potentiodynamic behavior of silver deposition and dissolution was similar to that obtained in the absence of the additive. Also, using data from the Raman spectra in both ex situ and in situ modes, it was determined that $\mathbf{H}_{2} \mathbf{P i c}^{+}$species were not adsorbed on the silver crystallites. However, by increasing the concentration of PA, it was possible to detect the adsorption of zwitterion and anion species, whose concentrations in the bulk solution were extremely low. Moreover, in the voltammograms at pH 3.0 with low PA concentration, two cathodic peaks were detected, which were associated with the electroreduction of the free $\mathrm{Ag}^{+}$ions and $[\mathrm{Ag}(\mathrm{Pic})]$ complexes. The deposition process was simplified to a single reduction wave, attributed to the metal complexes $[\mathrm{Ag}(\boldsymbol{P i c})]$ when the electrolyte contained a larger additive concentration as in the case of $\mathrm{pH}$ 6.5. In situ SERS spectra confirmed that the adsorbed species at $\mathrm{pH} 3.0$ and 6.5 was the anion. A configuration for the adsorption of PA (zwitterion and anion) molecules with the aromatic ring plane perpendicular to the Ag surface was established by the in situ and ex situ Raman spectra. The zwitterion species interacted with the silver surface only by the $\mathrm{COO}^{-}$functional group and the anion through the $\mathrm{N}$ atom in the pyridinic ring and one of the oxygen atoms of the $\mathrm{COO}^{-}$group. It is important that the $\mathrm{ClO}_{4}{ }^{-}$ion coadsorption was detected in the whole potential range scanned. In addition, the spectroscopic results confirmed the decrease in the value of the effective acid dissociation constant of PA at the electrode/solution interface, compared to the bulk solution.

Finally, the enhancement of Raman intensity was directly related to the morphology and size of the silver crystallites, which were optimal for producing the SERS effect of the adsorbates, even that of the HOPG surface. The maximum SERS signals of PA molecules were obtained at $\mathrm{pH} 3.0$ in the presence of $0.5 \mathrm{mM} \mathrm{PA}$, being a particular active SERS substrate given by the Ag particles with a globular flower-like structure, which supported intense local fields in the many deep gaps present between the flakes.

\section{ASSOCIATED CONTENT}

\section{Supporting Information}

Distribution curves of PA species in solution and calculated standard potential values, DFT of molecular structures, stability energies, and vibrational assignments for PA complex models. This material is available free of charge via the Internet at http://pubs.acs.org.

\section{AUTHOR INFORMATION}

\section{Corresponding Authors}

*E-mail: glacconi@mail.fcq.unc.edu.ar; gabriela.lacconi@gmail.com. Phone: +54-351-5353866, int. 53538. Fax: +54351-4334188.

*E-mail: mlatempe@iq.usp.br.

\section{Notes}

The authors declare no competing financial interest.

\section{ACKNOWLEDGMENTS}

The authors are grateful to Dr. A. Granados for his help with the ${ }^{1} \mathrm{H}$ NMN spectra analysis This research has been supported with funds from CNPq, FAPESP, CONICET, FONCyT, SECyT-UNC, PME 1544, and Central Analitica-IQ-USP (FEG-SEM facilities). G.F.S.A. thanks FAPESP for fellowships, and M.L.A.T. thanks CNPq for the research fellowship.

\section{REFERENCES}

(1) Miranda-Hernández, M.; Palomar-Pardavé, M.; Batina, N.; González, I. Identification of Different Silver Nucleation Processes on Vitreous Carbon Surfaces from an Ammonia Electrolytic Bath. J. Electroanal. Chem. 1998, 443, 81-93.

(2) Plieth, W. Additives in the Electrocrystallization Process. Electrochim. Acta 1992, 37, 2115-2121. 
(3) Tang, S.; Meng, X.; Lu, H.; Zhu, S. PVP-assisted Sonoelectrochemical Growth of Silver Nanostructures with Various Shapes. Mater. Chem. Phys. 2009, 116, 464-468.

(4) Penner, R. M. Mesoscopic Metal Particles and Wires by Electrodeposition. J. Phys. Chem. B 2002, 106, 3339-3353.

(5) Ustarroz, J.; Hammons, J. a.; Ingelgem, Y.; Van Tzedaki, M.; Hubin, A.; Terryn, H. Multipulse Electrodeposition of Ag Nanoparticles on HOPG Monitored by In-situ by Small-Angle X-ray Scattering. Electrochem. Commun. 2011, 13, 1320-1323.

(6) Hubin, A.; Gonnissen, D.; Simons, W.; Vereecken, J. Spectroelectrochemical Study of the Influence of Ligand Adsorption on the Reaction Rate of the Electrodeposition of Silver Complexes. J. Electroanal. Chem. 2007, 600, 142-150.

(7) Ortiz-Aparicio, J.; Meas, Y.; Trejo, G.; Ortega, R.; Chapman, T.; Chainet, E. Effects of Organic Additives on Zinc Electrodeposition from Alkaline Electrolytes. J. Appl. Electrochem. 2013, 43, 289-300.

(8) Azzaroni, O.; Schilardi, P. L.; Salvarezza, R. C.; Arvia, A. J. Smoothening Mechanism of Thiourea on Silver Electrodeposition. Real Time Imaging of the Growth Front Evolution. Langmuir 1999, $15,1508-1514$.

(9) Márquez, K.; Staikov, G.; Schultze, J. W. Silver Deposition on Silicon and Glassy Carbon. A Comparative Study in Cyanide Medium. Electrochim. Acta 2003, 48, 875-882.

(10) Temperini, M. L. A.; Sala, D.; Lacconi, G. I.; Gioda, A. S.; Macagno, V. A.; Arvia, A. J. Correlation Between SERS of Pyridine and Electrochemical Response of Silver Electrodes in Halide-free Alkaline Solutions. Langmuir 1988, 4, 1032-1039.

(11) Ma, C.; Harris, J. M. Surface-Enhanced Raman Scattering Study of the Kinetics of Self-Assembly of Carboxylate-Terminated nAlkanethiols on Silver. Langmuir 2012, 28, 2628-2636.

(12) Barthelmes, J.; Plieth, W. SERS Investigations on the Adsorption of Pyridine Carboxylic Acids on Silver- Influence of $\mathrm{pH}$ and Suporting Eletrolyte. Electrochim. Acta 1995, 40, 2487-2490.

(13) Oriňáková, R. Andersson Electrochemical Deposition of SERS Active Nanostructured Silver Films. Int. J. Electrochem. Sci. 2013, 8, $80-99$.

(14) Lin, Z.-B.; Tian, J.-H.; Xie, B.-G.; Tang, Y.-A.; Sun, J.-J.; Chen, G.-N.; Ren, B.; Mao, B.-W.; Tian, Z.-Q. Electrochemical and in Situ SERS Studies on the Adsorption of 2-Hydroxypyridine and Polyethyleneimine During Silver Electroplating. J. Phys. Chem. C 2009, 113, 9224-9229.

(15) Vázquez, C. I.; Lacconi, G. I. Nucleation and Growth of Silver Nanostructures onto HOPG Electrodes in the Presence of Picolinic Acid. J. Electroanal. Chem. 2013, 691, 42-50.

(16) Portela, A. L.; López Teijelo, M.; Lacconi, G. I. Mechanism of Copper Electrodeposition in the Presence of Picolinic Acid. Electrochim. Acta 2006, 51, 3261-3268.

(17) Portela, A. L.; Lacconi, G. I.; López Teijelo, M. Nicotinic Acid as Brightener Agent in Copper Electrodeposition. J. Electroanal. Chem. 2001, 495, 169-172.

(18) Quiroga-Argañaraz, M. B.; Vázquez, C. I.; Lacconi, G. I. Copper Electrodeposition onto Hydrogenated $\mathrm{Si}(111)$ Surfaces: Influence of Thiourea. J. Electroanal. Chem. 2010, 639, 95-101.

(19) Park, S. M.; Kim, K.; Kim, M. S. Adsorption of Picolinic and Nicotinic Acids on a Silver Sol Surface Investigated by Raman Spectroscopy. J. Mol. Struct. 1995, 344, 195-203.

(20) Barthelmes, J.; Pofahl, G.; Plieth, W. pH Dependent Raman Spectra of Nicotinic Acid- Spectra of Aqueous Solutions and Surface Enhanced Raman Spectra on Silver Electrodes. Ber. Bunsenges. Phys. Chem. 1992, 96, 1055-1060.

(21) Noda, L. K.; Sala, O. SERS Effect of Isonicotinic Acid Adsorbed on a Copper Electrode. J. Mol. Struct. 1987, 162, 11-17.

(22) Barthelmes, J.; Plieth, W. Field Dependence of the Protonation Equilibrium of 2-pyridinecarboxylic Acid on Copper in Sulfuric Acid. $J$. Chem. Soc., Faraday Trans. 1997, 93, 1321-1324.

(23) Wen, R.; Fang, Y. Adsorption of Pyridine Carboxylic Acids on Silver Surface Investigated by Potential-dependent SERS. Vib. Spectrosc. 2005, 39, 106-113.
(24) Reents, B.; Plieth, W.; Macagno, V. A.; Lacconi, G. I. Influence of Thiourea on Silver Deposition: Spectroscopic Investigation. J. Electroanal. Chem. 1998, 453, 121-127.

(25) Lacconi, G.; Reents, B.; Plieth, W. Raman Spectroscopy of Silver Plating from a Cyanide Electrolyte. J. Electroanal. Chem. 1992, 325, 207-217.

(26) Bozzini, B.; Mele, C.; Tondo, E. A SERS Investigation of $\mathrm{Cu}$ Electrodeposition in the Presence of the Model Leveller 4-\{2-[1-(2cyanoethyl)-1,2,3,4-tetrahydroquinolin-6-yl] diazenyl $\}$ Benzonitrile. Electrochim. Acta 2010, 55, 3279-3285.

(27) Pötzschke, R. T.; Gervasi, C. A.; Vinzelberg, S.; Staikov, G.; Lorenz, W. J. Nanoscale Studies of Ag Electrodeposition on HOPG (0001). Electrochim. Acta 1995, 40, 1469-1474.

(28) Ng, K. H.; Liu, H.; Penner, R. M. Subnanometer Silver Clusters Exhibiting Unexpected Electrochemical Metastability on Graphite. Langmuir 2000, 16, 4016-4023.

(29) Becke, A. D. Density-functional Thermochemistry. III. The Role of Exact Exchange. J. Chem. Phys. 1993, 98, 5648-5652.

(30) Lee, C.; Yang, W.; Parr, R. G. Development of the Colle-Salvetti Correlation-energy Formula into a Functional of the Electron Density. Phys. Rev. B 1988, 37, 785-789.

(31) Stevens, W. J.; Basch, H.; Krauss, M. Compact Effective Potentials and Efficient Shared Exponent Basis Sets for the First and Second Row Atoms. J. Chem. Phys. 1984, 81, 6026-6033.

(32) Stevens, W. J.; Krauss, M.; Basch, H.; Jasien, P. G. Relativistic Compact Effective Potentials and Efficient, Shared-exponent Basis Sets for the Third-, Fourth-, and Fifth-row Atoms. Can. J. Chem. 1992, 70, $612-630$.

(33) Frisch, M. J.; Trucks, G. W.; Schlegel, H. B.; Scuseria, G. E.; Robb, M. A.; Cheeseman, J. R.; Scalmani, G.; Barone, V.; et al. Gaussian 09, Revision B.01; Gaussian, Inc.: Wallingford, CT, 2009.

(34) Collier, W. B.; Magdo, I.; Klots, T. D. Infrared and Raman Spectra of Bicyclic Molecules Using Scaled Noncorrelated and Correlated Ab Initio Force Fields. J. Chem. Phys. 1999, 110, 57105720.

(35) Kotrlý, S.; Šůcha, L. Handbook of Chemical Equilibria in Analytical Chemistry; Ellis Horwood Ltd.: Chichester, England, 1985.

(36) Liang, Y.; Noda, L. K.; Sala, O. Polarizability and Concentration Effects on the Raman Spectra of Picolinic Acid Species in Aqueous Solution. J. Mol. Struct. 2000, 554, 271-277.

(37) Wang, L.-R.; Fang, Y. UV-Raman Study and Theoretical Analogue of Picolinic Acid in Aqueous Solution. J. Mol. Spectrosc. 2005, 234, 137-142.

(38) Miller, A. G.; Macklin, J. W. Vibrational Spectroscopic Studies of Sodium Perchlorate Contact Ion Pair Formation in Aqueous Solution. J. Phys. Chem. 1985, 89, 1193-1201.

(39) Wilson, E. B. The Normal Modes and Frequencies of Vibration of the Regular Plane Hexagon Model of the Benzene Molecule. Phys. Rev. 1934, 45, 706-714.

(40) Zoval, J. V.; Biernacki, P. R.; Penner, R. M. Implementation of Electrochemically Synthesized Silver Nanocrystallites for the Preferential SERS Enhancement of Defect Modes on Thermally Etched Graphite Surfaces. Anal. Chem. 1996, 68, 1585-1592.

(41) Alsmeyer, Y. W.; McCreery, R. L. Surface-enhanced Raman Spectroscopy of Carbon Electrode Surfaces Following Silver Electrodeposition. Anal. Chem. 1991, 63, 1289-1295.

(42) Temperini, M. L. A.; Lacconi, G. I.; Sala, O. Raman Spectroscopy Investigation of the Silver Oxide/silver Electrode: Influence of Experimental Conditions. J. Electroanal. Chem. 1987, 227, 21-28.

(43) Mayer, P.; Holze, R. Pyridine as a Probe Molecule for Surface Enhanced Raman Spectroscopy of the Silver-modified Glassy Carbon/ Solution Interface. Surf. Sci. 2003, 522, 55-63.

(44) Aroca, R. F.; Clavijo, R. E.; Halls, M. D.; Schlegel, H. B. SurfaceEnhanced Raman Spectra of Phthalimide. Interpretation of the SERS Spectra of the Surface Complex Formed on Silver Islands and Colloids. J. Phys. Chem. A 2000, 104, 9500-9505.

(45) Moskovits, M.; Suh, J. S. Surface Selection Rules for SurfaceEnhanced Raman Spectroscopy: Calculations and Application to the 
Surface-Enhanced Raman Spectrum of Phthalazine on Silver. J. Phys. Chem. 1984, 88, 5526-5530.

(46) Moskovits, M.; Suh, J. S. The Geometry of Several Molecular Ions Adsorbed on the Surface of Colloidal Silver. J. Phys. Chem. 1984, 88, 1293-1298.

(47) Creighton, J. A. Surface Raman Enhacement Electromagnetic Factors for Molecules at the Surface of Small Isolated Metal Spheres: The Determination of Adsorbate Orientation from SERS Relative Intensities. Surf. Sci. 1983, 124, 209-219.

(48) Stern, D. A.; Laguren-davidson, L.; Frank, D. G.; Cui, J. Y.; Lin, C.; Lu, F.; Salaita, G. N.; Walton, N.; Zapien, D. C.; Hubbard, A. T. Potential-Dependent Surface Chemistry of 3-Pyridinecarboxylic Acid (Niacin) and Related Compounds at $\mathrm{Pt}(111)$ Electrodes. J. Am. Chem. Soc. 1989, 111, 877-891.

(49) Adsorption of Molecules at Metal Electrodes; Lipkowski, J., Ross, P. N., Eds.; VCH: Weinheim, 1992.

(50) Brolo, A. G.; Irish, D. E. The Adsorption and Orientation of Pyrazine on Silver Electrodes: a Surface Enhanced Raman Scattering Study. J. Electroanal. Chem. 1996, 414, 183-196.

(51) Sant'Ana, A. C.; Alves, W. A.; Santos, R. H. A.; Ferreira, A. M. D.; Temperini, M. L. A. The Adsorption of $2,2^{\prime}: 6^{\prime}, 2^{\prime \prime}$-Terpyridine, $4^{\prime}$ (5-Mercaptopentyl)-2,2':6 $6^{\prime}, 2^{\prime \prime}$-Terpyridinyl, and Perchlorate on Silver and Copper Surfaces Monitored by SERS. Polyhedron 2003, 22, 16731682.

(52) Li, W.; Hsiao, G. S.; Harris, D.; Nyffenegger, R. M.; Virtanen, J. A.; Penner, R. M. Mechanistic Study of Silver Nanoparticle Deposition Directed with the Tip of a Scanning Tunneling Microscope in an Electrolytic Environment. J. Phys. Chem. 1996, 100, 20103-20113.

(53) Ma, C.; Harris, J. M. Surface-enhanced Raman Spectroscopy Investigation of the Potential-dependent Acid-base Chemistry of Silver-immobilized 2-mercaptobenzoic Acid. Langmuir 2011, 27, 3527-35233.

(54) Vázquez, C. I. Electrochemical Formation of Metallic and Bimetallic Nanostructures. Influence of Organic Compounds, $P h D$ Thesis. Facultad de Cs. Químicas, Universidad Nacional de Córdoba: Argentina, 2012.

(55) Tekin-Celebi, S.; Solak, A.; Ustundag, Z.; Demirci, S. Determination of $\mathrm{pKa}$ of Benzoic Acid- and P-aminobenzoic Acidmodified Platinum Surfaces by Electrochemical and Contact Angle Measurements. Chem. Pap. 2012, 66, 1146-1156.

(56) Imai, Y.; Kurokawa, Y.; Hara, M.; Fukushima, M. Observation of SERS of Picolinic Acid and Nicotinic Acid Using Cellulose Acetate Films Doped with Ag Fine Particles. Spectrochim. Acta, Part A 1997, 53, 1697-1700.

(57) Shegai, T.; Vaskevich, A.; Rubinstein, I.; Haran, G. Raman Spectroelectrochemistry of Molecules Within Individual Electromagnetic Hot Spots. J. Am. Chem. Soc. 2009, 131, 14390-14398.

(58) Kaczor, A.; Malek, K.; Baranska, M. Pyridine on Colloidal Silver. Polarization of Surface Studied by Surface-Enhanced Raman Scattering and Density Functional Theory Methods. J. Phys. Chem. C 2010, 114, 3909-3917.

(59) Ru, E. C. Le; Etchegoin, P. G. Principles of Surface Enhanced Raman Spectroscopy and Related Plasmonic Effects, 1st ed.; Elsevier: New York, 2009.

(60) Apell, P.; Xu, H.; Aizpurua, J.; Ka, M. Electromagnetic Contributions to Single-molecule Sensitivity in Surface-enhanced Raman Scattering. Phys. Rev. E 2000, 62, 4318-4324. 